\title{
Consequences of Perceived Crowding: A Meta-Analytical Perspective
}

\author{
Markus Blut* \\ Professor of Marketing \\ Aston Business School, Aston University \\ Aston Triangle, Birmingham, B4 7ET, UK \\ m.blut@aston.ac.uk \\ +441212044704
}

Gopalkrishnan R. Iyer

Professor of Marketing

College of Business, Florida Atlantic University

777 Glades Road, Boca Raton, FL 33431, USA

E-Mail: giyer@fau.edu

$+15612970917$

* Corresponding author 


\section{Consequences of Perceived Crowding: A Meta-Analytical Perspective}

While perceived crowding is an important construct in retailing literature, empirical findings on the consequences of this construct are mixed. This study uses meta-analytic techniques to combine the findings from 73 samples and more than 19,000 shoppers in order to both summarize and extend understanding of the consequences of human and spatial crowding in retail stores. It makes a threefold contribution. First, the examination of two distinct types of crowding - human crowding and spatial crowding - provides evidence that they have different impacts on customer satisfaction and behavioral responses. In general, spatial crowding has a negative impact on customer outcomes, whereas human crowding has positive effects. Second, a test of various theoretical perspectives on crowding demonstrates strong indirect effects of crowding through different mediators. While spatial crowding reduces shoppers' perceived control, human crowding has no such effect. Spatial crowding contributes to a negative evaluation of the store, whereas human crowding leads to a positive store evaluation. Both crowding types are related to positive and negative emotions experienced by shoppers. Thus, complex relationships are uncovered through the study of mediated effects, particularly within a comprehensive framework that integrates constructs and relationships from various theories. Third, the study of the impacts of various moderators indicates that human and spatial crowding display different effects depending on the retailer's offering (hedonic/utilitarian), retail type (store/agglomeration), employee support (high/low), customer type (new/existing), and the environment (cooperative/competitive). Study findings not only extend theory but also offer relevant implications for brick-and-mortar retail stores faced with the challenges of competing with new retail forms and the use of new technologies.

Keywords: human crowding, spatial crowding, perceived control, customer emotions, metaanalysis 
In a digital world, historical advantages of retail location now appear as liabilities of physical presence. Apart from the expensive costs of developing and maintaining a physical store, the brick-and-mortar store is also constrained by operational limitations of ensuring appropriate displays, stocks, atmosphere, and human interactions (Hortaçsu and Syverson 2015). Given increasing competition from non-store retailing, such as Internet retailing, traditional retail stores with physical locations are exploring various ways to survive and to remain relevant in the face of changing circumstances and customer preferences. Strategies to compete in the new world of retailing include transitioning to multi-channel retailing through developing an Internet retailing site to complement physical stores, deploying in-store technologies that enhance the shopping experience, and appealing to basic customer senses such as touch, smell, and taste that are not available to the online or mobile customer (Verhoef et al. 2009). Thus, these strategies attempt to turn the physical store space into a source of opportunities and distinctive competitive advantages.

However, while an increase in store traffic may contribute to enhancing sales, it may also detract from the customer's shopping experience. Since store space is often limited in brick-and-mortar stores, rather than being easily scalable as in Internet and mobile retailing, an increase in the number of customers at any given time implies a corresponding increase in customer perceptions of crowding (Menon and Kahn, 2002). This is also because the characteristics of the physical store, including its layout, impose restrictions on customers' control of their movements through the store (Menon and Kahn, 2002). Therefore, for brickand-mortar retailers, customer perceptions of crowding may be the key area of disadvantage compared with Internet retailers, which can accommodate an unlimited number of customers at any time, given the prevalence of fast Internet access and mobile technologies, and relatively easily scalable operations. 
The study of perceived crowding has gained momentum in the last two decades given its impacts on customers' affective and behavioral responses, including satisfaction (Eroglu et al. 2005). Perceived crowding adversely affects customer perceptions of shopping value, as well as their behavioral intentions and actual behaviors, especially when shopping is more task-oriented or viewed as a chore rather than a pleasurable activity (e.g., Hui and Bateson 1991). However, there is also evidence that the effects of perceived crowding may sometimes even be positive (Machleit et al. 1994). Therefore, it is important to understand not only the effects of perceived crowding, but also the specific conditions under which the effects have positive or negative impacts on shopper satisfaction, intentions, and behaviors. Further, customers' crowding perceptions primarily emanate in retail store and service contexts and are not easily countered by strategic and operational changes; on the other hand, the best analogous examples of website traffic overload and website clutter in the context of Internet retailing can be relatively more easily overcome by changes in technology (e.g., increase in bandwidth) and better website design, respectively. Therefore, a detail examination of perceived crowding and its effects might offer important insights to brick-and-mortar retail store managers and retail service providers. To this end, our integrative review of research on perceived crowding highlights not only what is currently known about customer perceptions of crowding in retail settings, but also areas that deserve future research attention.

Our meta-analysis aims to contribute to the understanding of perceived crowding in retail settings in three important ways - by revealing the impacts of different forms of crowding, by testing alternative theoretical explanations for the effects of perceived crowding on customer outcomes, and by examining the moderation of such effects due to customer and environmental characteristics. These are discussed seriatim. First, given the prior identification of two distinct forms of perceived crowding - human crowding and spatial crowding - within the marketing and retailing literature (Eroglu et al. 2005; Machleit et al. 
2000), we treat these two types of crowding as distinct customer perceptions and examine their different impacts on customer satisfaction, intentions, and behaviors. Human crowding in the retail context refers to perceptions of the number of individuals in the store and interactions between them, while spatial crowding perceptions stem solely from the physical features of the store, including the space available and the store configuration (Machleit et al. 1994). Even though both forms of crowding were previously referred to as "perceived crowding" in the literature, most researchers now treat human crowding and spatial crowding as distinct dimensions of perceived crowding, and also explore their impacts separately.

Second, our meta-analysis tests a comprehensive framework of the effects of human and spatial crowding and integrates various constructs and relationships advanced by individual theoretical perspectives. Prior research has identified the impacts of perceived crowding on various customer responses, and especially on customer satisfaction, intentions, and behavior (Machleit et al. 1994; Pons et al. 2014). Specific individual theoretical approaches not only suggest a direct impact of human and spatial crowding perceptions on customer outcomes, but also mediating effects of various factors, such as perceived control, emotions, and evaluation of the retail store. The comprehensive conceptual framework presented and tested here identifies the various mechanisms through which human and spatial crowding impact customer responses.

Third, the exploration of different effects of human and spatial crowding in our metaanalysis reveals not only interesting effects on customer outcomes, but also different effects when these relations are moderated by contextual characteristics. In contrast to several earlier presumptions of perceived crowding having solely negative impacts on shoppers, our metaanalysis highlights the opposing effects of human and spatial crowding within a common model, including how various customer and environmental moderations may diminish or enhance some of their effects ( $\mathrm{Li}$ et al. 2009). The identification of factors that could 
minimize negative impacts of crowding and/or conditions in which human crowding is perceived as positive by customers holds great promise for brick-and-mortar retailers in their strategies for enhancing the customer experience in a hypercompetitive retail environment.

The rest of this paper is organized as follows. After a review of the literature on perceived crowding, we develop our meta-analytic framework using various theoretical perspectives and offer some formal hypotheses for the key moderating effects. We then elaborate on our method and discuss the key findings. We conclude with several suggestions for future research, as well as managerial implications.

\section{REVIEW OF LITERATURE}

\section{Density and Crowding}

Early studies on crowding employed a biological perspective to understand the impact of infringement of a person's spatial domain due to an increase in population density (Baldassare 1978; Loo 1975; Stokols 1972a). Making a distinction between density and crowding, Stokols (1972b, p. 275) proposed that density involves "a spatial limitation," whereas crowding is an "experiential state ... in which the restrictive aspects of limited space are perceived by individuals exposed to them." As such, density is a "necessary antecedent, rather than a sufficient condition, for the experience of crowding." Stokols (1972a, p. 75) also clarified that "density is a univariate condition of limited space, without motivational overtones, whereas crowding is a multivariate phenomenon, resulting from the interaction of spatial, social, and personal factors." Later researchers adopted Stokols’'(1972a, 1972b) distinction of density and crowding and proposed individual and situational factors that may play a role in shaping perceptions. Simply stated, density was stated to refer to the "number of people per unit area" and was "objective," whereas crowding "involved a value judgment

\footnotetext{
${ }^{1}$ Some studies have considered density to have physical and social factors. As Loo (1975, p. 835) explained: "social density involves the comparative study of differing numbers of persons in the same amount of space, while spatial density involves the comparative study of the same numbers of people in differing amounts of space." Thus, we show this distinction in Web Appendix A, but do not discuss it here.
} 
requiring information about the setting, the desired activity, and the individual making the evaluation" (Shelby et al. 1989, p, 271). Thus, perceptions of crowding are affected by various factors such that increases in density do not always lead to corresponding increases in perceptions of crowding. ${ }^{2}$ Stokols (1972a) made a distinction between non-social and social crowding, which later provided the basis for the development of constructs of spatial and human crowding, respectively. These distinctions between density and crowding are further detailed in Web Appendix A.

\section{Effects of Crowding}

Prior research has identified that one primary source of psychological stress for the individual due to crowding is the availability and/or perception of availability of space in relation to the demand for it (Stokols 1972a). Negative evaluations and emotions emerge from a perceived threat to freedom to perform specific activities or tasks (Stokols 1976) and perceptions of a lack or loss of control over their environment (Schmidt and Keating 1979). Such negative consequences persist when individuals are unable to regain personal control or engage in successful coping strategies (Schmidt and Keating 1979; Stokols 1976). Within retailing, early studies explored the negative impacts of crowding on shopper satisfaction (Eroglu and Machleit 1990). In addition, perceived crowding was treated as a unidimensional construct (Hui and Bateson 1991), until Machleit et al. (1994) extracted the two factors of human and spatial crowding, leading to later studies treating these as distinct constructs.

Spatial crowding pertains only to the perceptions of space available to shoppers in a store (Mehta 2013). Spatial crowding relates only to the evaluation of the physical space; in other words, the inadequacy of space, or the restrictions of usable space, contributes to negative emotions and evaluations in some individuals (Stokols 1972a). An increase in the

\footnotetext{
${ }^{2}$ As Shelby et al. (1989, p. 271) cogently explained: "suppose there are 10 people in a room one day and 100 the next. Clearly density is higher on the second day, but is the room more crowded? If the room is a convention hall even 100 people is not a crowd, so that it would be uncrowded on both days. If it is a small office it might be crowded both times."
} 
number of people (other shoppers) in a given area (such as a store) contributes, in general, to enhanced perceptions of spatial crowding and, therefore, to increased physical constraints and feelings of confinement (Pons 2004). On the other hand, awareness of people occupying the same space contributes to perceptions of human crowding. Such perceptions stem not only from spatial restrictions but also from the relationship of the individual to people occupying the space (Stokols 1972a). ${ }^{3}$ Human crowding thus refers to the perception of the "number of individuals as well as the rate and extent of social interaction among people in a given environmental setting" (Machleit et al. 2000, p. 30).

In line with the original studies in psychology and environmental behavior, retailing research also found negative effects for spatial crowding. However, studies that measured human crowding found mixed results. Thus, the different impacts of human and spatial crowding call for more intense scrutiny of the mechanisms, conditions, and moderators by which they contribute to differences in satisfaction, intentions, and behaviors. Such an examination is provided in the next section.

\section{DEVELOPMENT OF THE META-ANALYTIC FRAMEWORK}

Research on crowding from various disciplines has relied on diverse theories to tease out the physiological and physiological impacts of crowding, as summarized in Web Appendix B. Our meta-analysis is informed by four distinct streams of research within retailing that explain the different consequent effects of human and spatial crowding. One stream of research focuses on the direct impacts of human and spatial crowding on customer outcomes and focuses on the ability of the individual to cope with the excessive stimuli in crowded situations (Stokols 1976). ${ }^{4}$ These studies referred to approach-avoidance theory and

\footnotetext{
${ }^{3}$ Environmental psychology considers the nature of social interactions within the crowd as well. Although competitive relationships are psychological stressors, cooperative relationships are often evaluated more positively, even under conditions of perceived crowding (see Figure 1).

${ }^{4}$ Some studies have referred to the optimal stimulation level theory and suggested that there may be an "optimum" level up to which the customer's feelings of pleasure might increase and then decline. These nonlinear effects have rarely been tested in the literature and are even more difficult to test in a meta-analysis.
} 
the adaptation/coping theory and offered that customers may avoid certain stores and enact behavioral adaptation strategies (such as going elsewhere to purchase) in order to function effectively in the crowded environment (Mehta 2013). A second research stream contends that human and spatial crowding reduce the individual's ability to influence and control the environment. Perceived control is, therefore, a key mediator in the impacts of crowding on customer responses since it affects customer perceptions of freedom and adversely impacts goal attainment (Brehm 1989; Hui and Bateson 1991; Van Rompay et al. 2008). A third and more recent stream of studies focuses on customer feelings about crowded stores. Studies in this stream use theories such as the Mehrabian-Russell model and the schema discrepancy theory and argue that crowding may lead to both positive and negative emotions, and that these emotions in turn impact customers' behavioral reactions (Baker and Wakefield 2012). Finally, a fourth literature stream relates human and spatial crowding to the beliefs of an individual customer about the store and its merchandise. These studies refer to inference theory and the servicescape model to explain that customers form inferences about stores based on environmental cues (Baker et al. 1994). Panel A of Table 1 summarizes the use of various theories in crowding research within retailing.

[Insert Table 1 about here]

\section{Direct and Mediating Effects of Crowding}

We use the above theoretical explanations to justify the various direct and mediating effects in our meta-analytical framework. Crowding studies often focus on a single theory when analyzing crowding effects. The various models proposed by different theoretical perspectives are mapped in Figure 1.

[Insert Figure 1 here]

\section{(1) Coping Theory and the Optimal Social Contact Concept}


A crowded shopping environment interferes with the shopper's goal attainment.

Shoppers are less likely to achieve their goals when too many other shoppers are also in the store (human crowding), or when limited space leads to perceptions of restricted movement (spatial crowding) (Stokols 1972b). In both crowding conditions, customers may engage in coping behaviors (Eroglu and Machleit 1990). ${ }^{5}$ According to Lazarus and Folkman (1984, p. 141), coping refers to "changing cognitive and behavioral efforts to manage specific external and/or internal demands that are appraised as taxing or exceeding the resources of the person.” Cognitive and behavioral coping strategies may have different impacts (Dion 2004). Cognitive coping strategies change the way in which the situation is attended to or interpreted by customers (e.g., psychological withdrawal), while behavioral coping strategies are problem-oriented and try to modify the actual situation (e.g., behavioral withdrawal). Decreased shopping satisfaction and lowered behavioral intentions represent forms of psychological withdrawal (Harrell et al. 1980), whereas changes in actual behavior such as postponement of purchases represent one form of behavioral withdrawal (Dion 2004).

Some prior studies have indicated positive direct effects of human crowding (though not of spatial crowding). Eroglu et al. (2005) explain this positive effect using optimal social contact theory, initially developed by Allport (1954) to explain how intergroup contact could reduce social tensions and intergroup prejudice. In other words, greater social contact helps counter predispositions and enhance tolerance and acceptance of others, and even leads to affective (liking) dispositions (Pettigrew 1998; Pettigrew and Tropp 2006). Extending this theory to marketing, customers in a group situation, such as when shopping, may be more open to interaction with others and may, over time, even seek the presence of other customers. Shopping situations provide some of the facilitating conditions under which

\footnotetext{
${ }^{5}$ Most crowding studies have assessed the influence of crowding on coping strategies without considering emotions as a mediator, as suggested in various frameworks (Eroglu and Harrell 1986; Eroglu and Machleit 1990; Harrel and Hutt 1976). However, the general coping literature suggests that emotions may mediate the effects of crowding on coping (Folkman and Lazarus 1988). For example, Dion (2004) considered both the direct effects of crowing on coping strategies and the indirect effects through negative feelings.
} 
intergroup contact reduces social tensions; these include equal status as customers, common shopping goals, intergroup cooperation, and rules and norms set by the business (Allport 1954; Pettigrew 1998). ${ }^{6}$ Thus, intergroup contact, as in the case of human crowding situations, provide the facilitating conditions for creating affective ties, as well as enabling positive perceptions and effects (Eroglu et al. 2005). On the other hand, given that customers appreciate the presence other shoppers, they may feel isolated and lonely in empty stores (Altman and Chemers 1984); they may be dissatisfied with their shopping experience and may not patronize the retailer again.

\section{(2) Perceived Control Model}

The perceived control model proposes that control perceptions are the key mediator between crowding and the different outcomes thereof (Hui and Bateson 1991). Individuals experience a feeling of control when their environment supports goal attainment. Customers are less likely to behave positively toward a store when they perceive not being in control of the situation (Hui and Bateson 1991). Restrictions on movement due to spatial crowding clearly lead to such loss of control due to not being able to exit the space (Kruse 1986), but such perceptions could also emerge when retail stores are crowded with other shoppers. This is because human crowding is associated with social interference and that customers perceive the store environment to be more strongly influenced by other shoppers than by themselves and thus, interfering with their task performance (Kruse 1986; Madzharov et al. 2015).

\section{(3) Emotional Response Model}

The Mehrabian-Russell model suggests that emotions mediate the relationship between the environment and behavioral responses (Donovan et al. 1994; Mehrabian and Russell 1974). Referring to this model, Baker and Wakefield (2012) explained that crowding leads to

\footnotetext{
${ }^{6}$ Allport (1954) proposed several optimal conditions under which intergroup contact would reduce prejudice. However, Pettigrew and Tropp (2006), in a meta-analysis of research on intergroup contact theory, found that these conditions were not necessary for the positive effects of social contact; however, the conditions, including intergroup cooperation, served to enhance the positive effects of intergroup contact.
} 
stress and lowers shopping enjoyment. Studies from psychology have shown that disruptions of people's response sequence produces arousal (Mandler 1964) and that people interpret this arousal as positive or negative depending on the context (Schmidt and Keating 1979). In the context of crowding in retail stores, both spatial and human crowding are associated with feelings of confinement given restrictions on space or intrusion into personal space by others. Customers experience stress due to spatial crowding when stores feel confining (Machleit et al. 1994). When customers have inadequate space, they may conclude that the overall situation is unpleasant, and they may experience negative emotions such as anxiety and stress (Stokols 1972b), and therefore be less likely to enjoy their shopping experience. However, a number of studies have also observed that human crowding has a positive influence on, for example, the pleasure experienced by customers. Li et al. (2009) explained that "shoppers' perceptions of human crowding during shopping do not necessarily evoke negative emotions, but rather evoke positive feelings" (p. 644). Thus, human crowding contributes to the "liveliness" of the store and customers feel aroused when surrounded by other shoppers. Das and Varshneya (2017) indicated that crowded stores attract customers' interest, making customers keen to explore those stores; therefore, human crowding may have positive effects.

\section{(4) Inference Theory}

Prior research has suggested that customers use crowding as a cue to make inferences that shape their evaluation of the retailer and the merchandise (Baker et al. 2002; Eroglu et al. 2005; Grewal et al. 2003). While crowded stores may lead to negative evaluations, Machleit et al. (1994) speculated that high store traffic can create the image that the store is interesting or unusual, and has "valuable" merchandise or services. The presence of other customers in the store may serve as a cue for evaluating the store as reputed and offering high quality merchandise (Tse et al. 2002). Human crowding can, therefore, serve as a cue for positive store evaluation. Similarly, inferences made from spatial crowding cues may also lead to 
mixed impacts on customer evaluations. Lee et al. (2011, p. 133) argued that "[a] spatially crowded store might convey a discount store image" - in other words, cause negative perceptions of the store. However, Baker et al. (1994) noted that while discount stores typically limit the space available for shopping and also convey a cheaper store image, such spatial crowding may actually be a cue for good value for money. Customers may infer stores having more space available for shopping to be attracting a higher social class and, therefore, may have positive evaluations of those store (O’Guinn et al. 2015). Thus, prior literature has suggested mixed impacts of both crowding types on store evaluations. The effects suggested by the various theoretical perspectives are presented in Figure 1.

\section{Integrating the Various Theoretical Perspectives}

Models with direct effects of human and social crowding suggested by each theory were tested and reported in the results sections. Moreover, in an integrated model, we explore the impacts of human and spatial crowding on customer outcomes through control perceptions, emotions, and store evaluation, assessing the potential for serial mediation. ${ }^{7}$ While testing the individual theoretical perspectives may provide some insights into the effects of spatial and human crowding, Palmatier et al. (2007) stressed the importance of testing different perspectives in one comprehensive model to assess their relative impacts. This comprehensive model is presented in Figure 2 and further elaborated in the next section.

\section{[Insert Figure 2 here]}

\section{Hypotheses on Moderating Effects}

One of the more interesting and unexplored avenues for analysis afforded by our metaanalysis is the examination of various pertinent moderators in the impacts of spatial and human crowding on the various outcomes. This comprehensive model that includes various

\footnotetext{
${ }^{7}$ Literature justifies interrelations between mediators. Hui and Bateson (1991) suggested that control perceptions influence the experience of customer emotions since loss of control reduces the experience of positive emotions (i.e., pleasure). Mattila (1998) emphasized the importance of emotions for information decoding in judgment decisions, therefore suggesting that positive (negative) emotions experienced by shoppers enhance (diminish) their store evaluations.
} 
moderators, some of which are only suggested but not explicitly tested in the literature, is presented in Figure 2. We derive hypotheses only for the moderator effects. One study (Machleit et al. 2000) examined retail format differences and found that the relationship between human crowding and satisfaction was non-significant for discount stores. Some studies on crowding have examined moderators related to the customer, such as crowding expectations and personal tolerance of crowding. However, the literature has given some indication of various other potential contextual moderators. For example, effects of human crowding may be different in utilitarian (e.g., banking) and hedonic (e.g., bar) settings (Hui and Bateson 1991). Pons et al. (2006) also found that the presence of a large number of people in leisure services enhances the customer experience. However, such differences in these settings have not been assessed for spatial crowding. According to Hui and Bateson (1991), the impacts of crowding on customer outcomes may vary based on the retail context itself (van Rompay et al. 2008). Based on our examination of accumulated studies, we identified five moderators: retail offering (hedonic/utilitarian), retail type (store/agglomeration), employee support (high/low), customer type (new/existing), and the environment (cooperative/competitive). Based on prior studies and the main effects from our meta-analysis (Table 2), we hypothesize the impacts of moderating variables on the positive effects of human crowding and the negative effects of spatial crowding on outcome variables as below.

Hedonic/utilitarian shopping. Human crowding is proposed to have a stronger (weaker) positive effect depending on whether the context is hedonic or utilitarian. In hedonic contexts, customers engage in "shopping for fun and enjoyment, and shopping to satisfy needs unrelated to the purchase of products," whereas customers in utilitarian contexts engage in shopping for "economic and utilitarian reasons with no inherent pleasure derived from the shopping experience" (Baker and Wakefield 2012, p. 793). Baker and Wakefield 
(2012) further explored the impacts of social versus task shopping on patronage intentions and found that the impacts had opposing effects based on the mediating impacts of excitement and stress, respectively. Their results offer insight into why effects of hedonic (social) and utilitarian (task) contexts may lead to different impacts on customer outcomes. Some studies have suggested that human crowding may be perceived more positively in hedonic than in utilitarian settings. For example, Kim, Lee, and Sirgy (2016) explained that in hedonic contexts, human crowding may be perceived as "good crowding" and contribute positively to the individual experience. They argued that hedonic situations are more likely than utilitarian settings to need crowds in order to produce the desired customer experience. Another explanation could be derived from optimal social contact theory and intergroup contact theory (Eroglu et al. 2005). As elaborated earlier, intergroup contact theory has been invoked in the study of crowding to argue that uncrowded spaces may contribute to isolation and lower stimulation level for customers (Eroglu et al. 2005). In contrast, in crowded but hedonic contexts people may seek out others and it is possible that contact will reduce any potential negative perceptions of human crowding. Therefore, in hedonic settings, human crowding may have a stronger positive impact; in fact, in hedonic contexts, human crowding may be a welcoming experience, as argued by Noone and Mattila (2009) from their study of extended service encounters. Service contexts such as sitting down for a relaxing meal at a restaurant can be a pleasurable or hedonic experience. In such contexts, Noone and Mattila (2009) argue that customers are "less bothered by the presence of others," since such crowding does not affect their ultimate consumption goal of an enjoyable meal (p. 33). In contrast, crowds impede customers in their consumption goals in utilitarian settings (Noone and Matilla 2009), since human crowding in such settings adversely affects shopping tasks and goals. Hui and Bateson (1991) also compared human crowding effects in utilitarian 
(banking) and hedonic (bar) settings, and concluded that there are positive behavioral responses in hedonic settings. Hence:

H1a: The positive effects of human crowding on customer satisfaction, behavioral intentions, and actual behavior are stronger in hedonic shopping contexts than in utilitarian shopping contexts.

Spatial crowding is expected to display negative effects on customer outcomes which may also vary in strength depending on this moderator. Spatial crowding perceptions in hedonic contexts may lead to negative effects since restrictions on movement curtail the enjoyment otherwise derived from shopping. In utilitarian contexts, shoppers are more interested in efficiently completing the shopping trip with minimal effort (Mehta 2013). Their primary goal is to purchase the desired products, with no intent to derive satisfaction from the shopping activity itself. Since completion of the shopping trip is more important in utilitarian contexts, customers react more negatively to disruptions from spatial crowding. This is because such crowding impedes their goal achievement and imposes behavioral restrictions (Eroglu and Machleit 1990). Hence, the negative effects of spatial crowding on customer outcomes are stronger in utilitarian shopping settings. Thus:

H1b: The negative effects of spatial crowding on customer satisfaction, behavioral intentions, and actual behavior are weaker in hedonic shopping contexts than in utilitarian shopping contexts.

Single store/agglomeration. We propose that the negative effects of spatial crowding on customer outcomes are stronger for agglomerations, such as malls, shopping streets, night markets, and weekly markets, as compared with stand-alone stores or single stores.

Agglomerations attract customers because of the greater number of stores, product categories, and prices. Such assortments of stores and merchandise are a distinctive feature of malls' “one-stop convenience" (Bloch et al. 1994), and malls enhance various dimensions of service convenience, such as decision, access, transaction, benefit, and post-service convenience. Given the importance of such service convenience, spatial crowding may generally be 
perceived more negatively in mall settings than in single-store contexts. By contrast, while customer responses are also negatively affected by spatial crowding in a single retail store, they can leave the store without making a purchase (Harrell et al. 1980). However, since the mall layout often hinders easy exit, spatial crowding in an agglomerated setting is likely to have more severe negative impacts as compared to single stores. For example, even temporary restrictions in movement such as due to minor construction work in the access areas of malls may often be unexpected and be viewed as a restriction on freedom. Therefore, spatial crowding may have stronger negative effects in agglomerations.

However, the impacts of human crowding are not affected by this moderator. Human crowding could also detract shoppers in agglomerated settings (such as malls) from browsing; however, the effects of spatial crowding would be more negative since perceptions of restricted movement in malls may be more enduring (Kim and Runyan 2011). As Van Rompay et al. (2008, p. 321) explained, human crowding perceptions vary when moving through the location, whereas spatial crowding "pose[s] more permanent and, by consequence, severe restraints." Similarly, Machleit et al. (2000, p. 40) had argued that "if the store were crowded on the space dimension, shoppers might have felt that they had less opportunity to change the environment." Evidence has suggested that agglomerations will have no notable impact on the influence of human crowding on customer outcomes. This is because of several factors relating to customer expectations and orientations. For one, marketplaces that have agglomerated traders and shops into souks, bazaars, and malls have been places for social gatherings and meeting with friends throughout history (Bloch et al. 1994). In addition, mall shoppers expect agglomerated retail areas to have a large number of people. Thus, we derive the following hypothesis only for the effects of spatial crowding: H2: The negative effect of spatial crowding on customer satisfaction, behavioral intentions, and actual behavior is weaker for single stores than for agglomerations. 
Employee support. Prior studies have found that employees are quite critical for the customers' shopping experience and outcomes. Apart from making the sale, store employees are boundary personnel who convey organizational strategy and service orientation (Rafaeli 1989). Mattila and Wirtz (2008, p. 563) suggested an interaction effect between employee assistance and human crowding. The appearance and behavior of store employees are critical for customer perceptions of the service level of the store (Baker et al. 1992), as well as their image of the store (Baker et al. 1994). As Hu and Jasper (2006) demonstrated, employeecustomer interactions could be an important social cue in the store environment that contributes to higher customer evaluations of the store image, enhanced pleasure, and positive behavioral intentions. Friendly and enthusiastic employees enhance customer perceptions of service quality (Baker et al. 1992). In addition, employees help customers cope when a large number of other shoppers are in the store (Baker et al. 1992), and it is very likely that friendly, enthusiastic, helpful, and empathetic employees enhance the positive impacts of human crowding on customer satisfaction and behavioral responses. Early research by Rafaeli and Sutton (1990) suggested that exchanges between store employees and customers are critical when stores are characterized by busyness, or "the extent to which a store was rapidly paced and crowded with customers" (p. 624).Thus, the positive effects of human crowding on the various consequence variables (e.g., satisfaction, intentions) are stronger for stores with supportive employees.

Although prior research on crowding has proposed that employee support moderates the effects only for human crowding, a similar rationale can also be extended to the moderation of employee support on the effects of spatial crowding. Store design cues enhance perceptions of convenience and thereby help facilitate customer goals as well as reduce customers' time and psychic costs (Baker et al. 2002). However, it is likely that when customers perceive the space available to them to be inadequate, leading them to feel 
uncomfortable, they engage in various coping strategies to deal with the situation. They may seek the assistance of employees to enable fulfillment of their goals (Mehta 2013). Some of the more common ways employees facilitate customer coping may be through providing information to help customers navigate the store, helping locate merchandise, or offering assistance that overcomes restrictions on movement and barriers to shopping. In situations of spatial crowding, customers can be expected to be less dissatisfied and display fewer negative behavioral responses when assisted by store employees. In other words, the negative effects of spatial crowding on the outcomes are weaker for stores with supportive employees. Hence,

H3: While the positive effects of (a) human crowding on customer satisfaction, behavioral intentions, and actual behavior are stronger for retail formats offering employee support than for those that do not offer such support, the negative effects of (b) spatial crowding are weaker.

New/existing customers. We expect human crowding effects to differ for new versus existing customers. When customers visit a specific store more often, they gain more expertise about the customer traffic patterns in that store (Machleit et al. 2000). Customer traffic often varies throughout the week, with more customers visiting stores during the weekend than on other days, and a store may experience more traffic in the evening during rush hours (Li, Kim, and Lee 2009). Customer traffic patterns also vary given the specific retailer, and only customers who have visited a store more than once previously know when the store is typically busy. New customers lack insights into customer traffic that may be in the store and, thus, may react less positively to human crowding since they may not have expected the store to be crowded (Machleit et al. 2000). Similar to customers forming judgments of service levels and store image (see Baker et al. 1992, 1994), customers also form expectations of the crowding they may encounter when visiting a store they have visited in the past. Prior research has shown that customers evaluate crowding in a context based on prior experience (Helson 1964). For example, Webb and Worchel (1993) argued that people form expectations based on prior experience and compare such expectations to the current 
situation. Thus, existing customers rely on expectations and prior experience as comparison standards for evaluating crowding (Webb and Worchel 1993). However, new customers may not have the luxury of prior experience as a comparison standard, and may compare the existing situation merely to expectations based on other factors. Citing prior research, Stokols (1972a, p. 80) stated that "newcomers to a situation of crowding tend to be more vulnerable to its adverse effects than persons who have had previous experience with crowded situations." Therefore, the positive effects of human crowding effects on various customer responses will be weaker for new customers than for existing customers.

These differences between new versus existing customers are proposed here only for human crowding (Machleit et al. 2000; Mehta 2013), for two reasons. First, spatial crowding perceptions emanate from the evaluation of the space - e.g., whether the area is spacious or confining, or contributes to feelings of being cramped (Harrell et al. 1980; Mehta 2013) and, even if such perceptions vary across customers, there is no basis to assert (or deny) that such perceptions may vary based on whether the customer is new to the store or is an existing patron. Second, spatial constraints that affect customer movement through the store are constant throughout the week, affecting both new and existing customers to the same extent. Therefore, we offer the following hypothesis for the moderation of new/existing customers on the effects of human crowding:

H4: The positive effects of human crowding on customer satisfaction, behavioral intentions, and actual behavior are weaker in the case of new customers than for existing customers.

Cooperative/competitive environments. The positive effects of human crowding are proposed to differ in strength for cooperative versus competitive environments. There is prior evidence from psychology to suggest that evaluation of the effects of crowding vary based on people's interpretation of the environment as cooperative or competitive. Such perceptions of the environment may depend upon how occupants of the space evaluate others sharing the 
same space. In competitive environments, individuals may perceive a restriction on freedom due to the presence of others; as a result, there may be jostling for territory that one considers one's own. The positive effects of human crowding on outcomes tend to be weaker in competitive environments. On the other hand, in cooperative environments, there may be a shared understanding that the restrictions are not due to others occupying the space but because of something else (e.g., involuntary confinement, as in prisons). Intergroup contact theory predicts that social contact reduces tensions and conflicts even in otherwise crowded situations (Pettigrew 1998). Further, research within psychology has extended the original thesis of intergroup contact theory and contends that social contact leads not only to favorable attitudes of others, but also to greater intergroup cooperation, with such cooperation even leading to friendship (Pettigrew et al. 2011). Thus, the positive effects of human crowding on outcomes tend to be stronger in cooperative environments.

In addition, the effects of cooperative environments are more pronounced for human crowding as opposed to spatial crowding. This is because while spatial crowding imposes a restriction on movement primarily due to physical and environmental constraints, the evaluation of human crowding, even if prima facie restrictive, is made after considering the social context. From the environmental perspective, we learn that design can induce greater social interactions and community spirit (Baldassare 1978). Baldassare (1978, p. 36) suggested that "forced contact and shared space will result in cooperation or communality and not conflict or withdrawal." In other words, human crowding situations that induce involuntary contact among individuals will lead to greater cooperation among individuals occupying the space. This is because human crowding involves a more focused evaluation of the context, as well as the people occupying the space (Loo 1975; Stokols 1972a). As Stokols (1972a, p. 75) stated, "an individual may feel crowded in the midst of strangers, but quite comfortable and secure in the presence of an equal number of friends." The interpretation of 
the crowded context depends upon the attributions made to the arousal caused by crowding, such that the consequent effects are more negative if the violation of personal space caused by crowding is attributed to others (Worchel and Teddlie 1976). Sinha and Mukherjee (1996) also showed that there is greater tolerance for crowding when there is higher cooperation among the occupants of a physical space. Thus:

H5: The positive effects of human crowding on customer satisfaction, behavioral intentions, and actual behavior are stronger for cooperative environments than for competitive environments.

Method moderators. The studies collected for the meta-analysis differed in several aspects of their research design, such as data collection method, respondents, and year of study. While some studies conducted surveys and asked shoppers about their actual in-store crowding experience, the crowding literature also contains a few experimental studies. In addition, student samples may produce stronger effect sizes than non-student samples because such samples are more homogeneous, which leads to lower error variance in measurement (Geyskens et al. 2009). Also, the year of the study is included as a moderator because counterintuitive findings are more likely to be published if they are in initial studies than if they are in follow-up studies (so-called Prometheus effect). ${ }^{8}$

\section{METHOD}

\section{Data Collection and Coding}

Electronic databases were the primary source for locating empirical studies for this meta-analysis, using keyword searches such as "crowding," "perceived crowding," "social crowding," "human crowding," and "spatial crowding." In addition to searching ABI/INFORM, Proquest, Scopus, Web of Science, Google Scholar, and EBSCO (Business Source Premier), the references cited in recent and relevant articles identified further studies. An extensive general search of the Web provided useful material as well. The literature

\footnotetext{
${ }^{8}$ This research assessed whether the crowding effects are stronger in studies testing both crowding types because the crowding measurements may not be independent of each other. No differences were observed for studies testing one type of crowding compared to studies assessing both types.
} 
search revealed, in line with a previous qualitative review (Mehta 2013), that the operationalization of crowding has been very heterogeneous in the past. Some studies examined overall crowding, combining human and spatial crowding items, whereas other studies explicitly differentiated between the crowding types. Some studies were conducted in contexts other than retailing. The present meta-study focuses specifically on both human crowding and spatial crowding. For the purposes of coding, we interpreted human crowding as the perception of the number of other shoppers in the premises and the associated social interactions, and spatial crowding as the perception of the space available to the shoppers in a store (see also Mehta 2013). In addition, we examine crowding specifically in a retail context. We scrutinized studies that measured perceived crowding but did not distinguish between human and spatial crowding. ${ }^{9}$ Most studies (49\%; 36 out of 73 samples) in this meta-analysis used items based on the crowding measurement developed by Machleit et al. (1994) (Panel B, Table 1). Other studies (12\%; 9 out of 73 ) adapted items from the semantic differential scales provided by Harrell, Hutt and Anderson (1980). Some studies used single items (11\%; 8 out of 73$)$, their own measurement (4\%; 3 out of 73$)$, or other scales $(23 \% ; 17$ out of 73$)$. The meta-analytic data includes 54 studies. Five of these studies are unpublished and were made available through contact with the authors. The complete list of studies is displayed in Web Appendix C. The study characteristics were extracted by two coders, with an agreement rate of $95 \%$. Coders used the construct definitions in Web Appendix D to classify the effect sizes.

\section{Integration of Effect Sizes}

Meta-analyses often use correlation coefficients as effect sizes, since these are scaleindependent and are frequently reported in collected studies. Since some crowding studies

\footnotetext{
${ }^{9} \mathrm{We}$ examined the items because some studies have labeled the variable crowding or perceived crowding and measured either only human or only spatial crowding under these labels (e.g., Gelbrich and Sattler 2014). Other studies have examined perceptions of density and used items from Machleit et al. (1994) or their own crowding items (e.g., Dion 1999). The meta-study excluded effect sizes for objective density manipulations (e.g., Pons et al. 2014). The only exception is when a study manipulated density in an experiment and the authors tested whether the two experimental groups differed from each other using a crowding scale.
} 
relied on experiments and did not report correlation coefficients, means and standard deviations were used to calculate the correlations. In some cases, standardized regression coefficients were transformed into correlations (Peterson and Brown 2005). When samples reported more than one correlation for the same relationship of interest, these correlations were averaged and reported as a single study to avoid giving too much weight to a specific study (Hunter and Schmidt 2004). In total, 1,512 effect sizes were extracted. Correlations had been reported in 73 independent samples in 54 articles. The cumulative sample size across all samples was 19,054 customers. Calculation of the average correlations followed the randomeffects approach to meta-analysis proposed by Hunter and Schmidt (2004). First, the reliability coefficients of the dependent and independent variables were used to correct for measurement errors. Each effect size was divided by the square root of the product of the two constructs' reliabilities. When a specific study did not report the required reliability information, the average reliability of that construct was used instead. Second, the reliabilityadjusted correlations were weighted by the sample size to correct for sampling errors. For each sample size-weighted and artifact-adjusted correlation, standard errors and 95\% confidence intervals were calculated. The calculated credibility intervals also suggest the extent to which moderators might account for the unexplained variance (Hunter and Schmidt 2004). We further assessed the heterogeneity in the effect size distribution by calculating the Q-statistic test of homogeneity. The possibility of publication bias was assessed using Rosenthal's (1979) fail safe N (FSN). The FSN refers to the number of studies averaging null results necessary to lower a significant relationship to a barely significant level $(\mathrm{p}=.05)$. The results are robust when FSNs are greater than $5 \mathrm{x} \mathrm{k}+10$, where $\mathrm{k}=$ the number of correlations. Furthermore, we calculated the binomial effect size display (BESD). The BESD indicates the likelihood of customers becoming dissatisfied (e.g., high human crowding) compared to a 
reference group (e.g., low human crowding) (see Grewal et al. 2018). The percentages give an indication of the practical relevance of examining human and spatial crowding effects.

\section{Estimation of the Structural Equation Model}

To test the comprehensive model with mediators, the meta-analysis employed structural equation modeling (SEM). A comprehensive correlation matrix of the collected effect sizes was compiled and included all the constructs in our conceptual framework. This matrix was the input for estimating the structural model using LISREL 9.2. The harmonic mean of all sample sizes $(\mathrm{N}=1,907)$ was used as the sample size for the calculations. All SEM constructs were measured with single indicators. The error variances were set to zero because measurement errors had already been considered when integrating the effect sizes.

\section{Moderator Analysis}

We conducted subgroup analysis to test moderators. We therefore reported the sample size-weighted and artifact-adjusted correlation for each level of the respective moderator when examining dummy-coded moderators. For continuous moderators, we correlated the effect sizes with the moderator variable (Pick and Eisend 2014). Except for the year of the study, which was measured on a discrete scale, each moderator variable was dummy-coded as follows: retail offering ( $1=$ hedonic; $0=$ utilitarian); retail type $(1=$ single store;

$0=$ agglomeration); employee support (1=high; $0=$ low); customer type (1=new customers; $0=$ existing customers); environment ( $1=$ cooperative; $0=$ competitive); research design (1=experiment; $0=$ survey); and sample (1=student; $0=$ non-student $).{ }^{10}$ We complemented these analyses with random effects meta-regression, because this approach allows the simultaneous examination of various study characteristics (Grewal et al. 2018). The literature contends that moderator analysis using a random-effects approach is better suited for

\footnotetext{
${ }^{10}$ The moderator models tested additional moderators to rule out alternative explanations for the observed effects. For instance, the authors tested the influence of discount (versus non-discount) stores, goods (versus services) retailing, conspicuous (versus non-conspicuous) consumption, emerging (versus non-emerging) markets, student (versus non-student) samples, and quality of the publication outlet.
} 
addressing primary research questions in meta-analyses than are those using the fixed-effects model (Hunter and Schmidt 2004). Reliability-corrected correlations were used as dependent variables and the study characteristics functioned as independent variables. In total, six regression models were calculated for each of the relationships between both crowding types and the three outcome variables.

\section{RESULTS}

\section{Descriptive Statistics}

As indicated in Table 2, human crowding has a positive effect on most of the outcome variables and spatial crowding has a negative effect on the various outcome variables, with a few exceptions. While prior studies had examined the effects of human crowding on positive emotions, store evaluation, satisfaction, and behavioral intentions, the impacts on customers' actual behavior and perceived control remained largely untested. Specifically, the results suggest that human crowding has a strong positive impact on store evaluation as displayed by the sample-weighted reliability adjusted average correlation ( $\mathrm{rc}=.16)$. The effect sizes for satisfaction (.06), behavioral intentions (.06), actual behavior (.06), and positive emotions (.07) are also positive albeit insignificant. While human crowding improves most outcomes and mediators, it also induces negative emotions (.32) and reduces control perception (-.12). These findings also give a preliminary reason for considering mediating mechanisms. Spatial crowding has received less prior attention than human crowding, and, even in such research, the effects of spatial crowding on positive emotions, satisfaction, and behavioral intentions have received the most attention. Spatial crowding exerts negative effects on most customer outcomes and mediators. For example, spatial crowding reduces customer satisfaction (-.23), actual behavior (-.05), and perceived control (-.28). It is also leads to the experience of negative emotions (.36). Also, the effects on behavioral intention (-.02) and store evaluation (-.12) are negative albeit insignificant. However, spatial crowding also displays a positive 
effect on positive emotions (.07). Again, results suggest potential indirect effects of spatial crowding through mediators. In addition, human crowding and spatial crowding dimensions share only $18 \%$ of variance with each other, and they can be treated as distinct constructs. Most relationships were found to be robust against publication bias (FSNs exceed tolerance levels). In addition, all Q-tests of homogeneity were significant, suggesting the need to conduct moderator analysis. ${ }^{11} \mathrm{We}$ also assessed whether outliers influenced the obtained results to determine whether the results are robust (Geyskens et al. 2009). We further found the absolute BESDs for mediators and outcomes to range from just $4 \%$ to as much as $113 \%$. This indicates that both types of crowding are important for explaining the distinct variance in several mediators/outcomes.

\section{[Insert Table 2 here]}

\section{Results of the SEM}

Five models were calculated to test the various theories discussed earlier and to assess whether constructs from these theories should be integrated into one model (Figures 1 and 2). These models were compared on the basis of explained variance in the dependent variables, the number of significant effects, and model fit. Model estimations used the correlation matrix as an input (Web Appendix E), and the results of the SEM are shown in Table 3. We excluded customer satisfaction from this analysis due to high correlations with other variables. The condition number of the calculated model is 4.296 ; hence, multicollinearity is not a serious issue (Jöreskog et al. 2016). Comparing Models 1-5 in Table 3 reveals that each model reports significant effects that are in line with the theory. Model 5, the integrated

\footnotetext{
${ }^{11}$ The need for moderator analysis was also assessed with the 75\% rule (Hunter and Schmidt 2004). Moderator analysis is warranted if less than $75 \%$ of variance in effect-size estimates is caused by artifacts (e.g., sample error). All relationships examined in the moderator analysis display an explained variance of less than $75 \%$, except for the spatial crowding-satisfaction relationship, for which the variance is $84 \%$.
} 
model, fits the data well and explains most variance. It was therefore used to examine the predictions of various theories. ${ }^{12}$

\section{[Insert Table 3]}

Coping theory and the optimal social contact concept propose that human and spatial crowding impact customer outcomes. We observe several differences for human and spatial crowding. The effect of human crowding on behavioral intentions is negative, whereas its effect on actual behavior is positive. Spatial crowding has a negative effect on actual behavior, while its effect on intentions is positive. Results thus provide some support for both theories. As suggested by the perceived control model, spatial crowding reduces the customer's control perceptions about their environment. While spatial control has a negative effect on perceived control, human crowding does not show such an effect. Thus, the results give some support for the mediating role of perceived control. The emotional response model suggests that emotions are key mediators between crowding and customer outcomes. The results indicate that both human and spatial crowding are positively related to negative emotions. The results also suggest that human and spatial crowding enhance positive emotions, as suggested by the emotional response model. This finding indicates the ambivalent nature of both crowding types. Hence, human crowding and spatial crowding differ little in their impacts on induced emotional responses. Inference theory proposes that crowding influences customers' beliefs about the store. Human crowding was found to be used as a cue by customers, as it positively influences store evaluation. For spatial crowding, we observed the opposite effect: it is also used as a cue by customers, but its influence on store evaluation is negative. The model further suggests that the different mediators are interrelated. With greater perceived control, individuals are likely to experience more positive and fewer negative emotions. Emotions also impact evaluation of the store; customers

\footnotetext{
${ }^{12}$ We ran an alternative model allowing some of the mediator residuals to correlate. This model has a worse fit $\left(\chi_{\mathrm{df}=2}^{2}=1,199 ; \mathrm{CFI}=.840 ; \mathrm{GFI}=.906 ; \mathrm{RMR}=.195 ; \mathrm{SRMR}=.176\right)$ than did the one presented in the paper.
} 
experiencing negative emotions evaluate the store more negatively, whereas positive emotions improve evaluations. To complement these findings, the indirect and total effects were calculated, as well as the ratios of indirect effect to total effects. Results suggest indirect effects of both crowding types on customer outcomes, with human crowding having stronger mediating effects than spatial crowding (Table 4). While perceived control is more important as mediator for spatial than human crowding, emotions are of equal importance as mediator.

[Insert Table 4 here]

\section{Results of Moderator Analysis}

We report the results of univariate moderator analysis in Table 5 displaying the mean effect sizes within each level of the respective moderator for the three outcome variables. We find that several human and spatial crowding effect are stronger (weaker) depending on different moderators. In some cases, the effects differ not only in strength but also in their direction with a positive effect for one level of the moderator and a negative for the other. The corresponding meta-regression results are reported in Web Appendix F.

Hedonic/utilitarian shopping. The moderator results in Table 5 suggest that the effect of human crowding on behavioral intentions is significantly stronger when examining hedonic ( $\mathrm{rc}=.11)$ rather than utilitarian shopping contexts (-.01). A similar moderating effect can be observed for actual behavior (hedonic: 23; utilitarian .02). These findings are in line with H1a. Contrary to our predictions in $\mathrm{H} 1 \mathrm{~b}$, we observe spatial crowding to display a negative effect on behavioral intentions in hedonic shopping contexts (-.21) and a positive effect in utilitarian contexts (.16). Customers in hedonic contexts are more bothered by spatial crowding than customers in utilitarian contexts.

[Insert Table 5 here]

Single store/agglomeration. The effects of spatial crowding also differ when comparing single stores with retail agglomerations $(\mathrm{H} 2)$. Spatial crowding has a negative effect on 
satisfaction which is significantly stronger for retail agglomerations (-.42) than single stores (-.17). However, spatial crowding also has a negative effect on behavioral intentions in single-store settings (-.10), but a positive effect in agglomeration settings (.24). Although not predicted, we observe human crowding to have a stronger positive effects on behavioral intentions for agglomerations (.09) than single stores (.03.). Human crowding also has a positive effect on satisfaction for single stores (.09), but a negative effect for agglomerations (-.05). Similar effects were observed for actual behavior (single store: .13; agglomeration: .07). These findings emphasize the importance to differentiate between customer's affective and behavioral responses when studying crowding in a retail context.

Employee support. The empirical evidence for employee support as a moderator is rather weak. Contrary to predictions in $\mathrm{H} 3 \mathrm{a}$, we observe a negative effect of human crowding on satisfaction when customers receive support (-.13) and a positive effect in contexts without support (.08). Also, the negative effect of spatial crowding on satisfaction is stronger for high support- (-.43) than low support-contexts (-.17). A similar moderating effect can be observed for behavioral intentions (H3b). It seems that provision of support makes customers realize that they are unable to cope with human and spatial crowding themselves, which they may not necessarily have noticed otherwise.

New/existing customers. The results suggest that several of the human crowding effects are moderated by customer type (H4). We observed that the effect of human crowding on satisfaction is negative for new customers (-.04) and positive for existing customers (.11). For the other outcomes, the positive effects are stronger for new customers than existing customers, including intentions (new: .08; existing: .02) and actual behavior (new: .17; existing: .05). Although not hypothesized, we find the negative effect of spatial crowding on satisfaction to be stronger for new customers (-.46) than existing customers (-.20). When 
examining intentions, the effect is also negative for new customers (-.06), but positive for existing customers (.04).

Cooperative/competitive environments. The results reveal that human crowding effects vary due to this moderator (H5). The positive effect of human crowding on intentions is stronger for cooperative (.09) than competitive environments (.01). The opposite effect was observed for satisfaction with a stronger effect in competitive (.07) than cooperative environments (.01). As expected, no differences were observed for spatial crowding.

Method moderators. The study year showed several significant effects suggesting human and spatial crowding effects to be stronger in more recent years. We also find some differences for the employed research design and sampling approach. Human and spatial crowding effects are stronger in surveys than experiments and the effects of both crowding types are stronger for nonstudent samples compared to student samples.

\section{GENERAL DISCUSSION}

Distinctive features of our meta-analysis of studies involving more than 19,000 respondents are the treatment of human and spatial crowding as distinct concepts, and an elaboration of their effects both directly and through mediators and moderators on various customer responses tested in prior empirical studies. An overview of the results is presented in Table 6. The discussion of key results below is organized in terms of the proposed contributions and insights obtained.

\section{[Insert Table 6 here]}

\section{Direct Impacts of Human and Spatial Crowding}

While early studies focused on the broader construct of "perceived crowding," our results show that the human crowding and spatial crowding constructs are quite distinct, as indicated not only by a low shared variance ( $18 \%$ only) and distinct direct effects (Table 2 ) but also by different effects through mediators and moderators (Table 6). In general, spatial 
crowding has a negative impact on customer outcomes, whereas human crowding has positive effects. Prior research has shown that crowding impedes customers from attaining their shopping objectives and hence, customers may evaluate their shopping experience negatively (e.g., Harrell et al. 1980). Therefore, we expected spatial crowding to have negative impacts on outcomes such as satisfaction, behavioral intentions, and actual behavior; our results confirm expectations except for the non-significant effect for behavioral intentions (Table 6). On the other hand, social contact due to crowding may reduce social tensions and provide the desired stimulation to shoppers. Thus, we expected a positive impact of human crowding on satisfaction, behavioral intentions and actual behavior. These effects, albeit insignificant (Table 2), confirm prior studies that have explicitly measured human crowding and found it to have a positive effect as compared to negative effects for spatial crowding.

Perceived control, positive and negative emotions, and store evaluation were offered as mediators in models 2, 3 and 4 (Figure 1). The direct effects of human and spatial crowding on these variables were also examined (Tables 2 and 6). Hui and Bateson (1991) suggested that customers feel a loss of control when they encounter crowded environments. Both spatial and human crowding would have negative impacts on perceived control even though the mechanisms by which they lead to such impacts may differ. Spatial crowding restricts movement and thus, the shopper's control of their own paths; on the other hand, the presence of other customers, as in human crowding, is associated with social interference and task performance (Madzharov et al. 2015). Our results confirm the negative effects of both spatial and human crowding on perceived control, though the effects of human crowding are nonsignificant. A fruitful avenue for future research would be to explicitly examine the different mechanism through which both crowding types lead to perceptions of loss of control.

One of the direct consequences of spatial crowding has been on customer emotions, such as stress, anger and anxiety (Stokols 1972b). Spatial crowding exacerbates such negative 
emotions and our meta-analysis results confirm this expectation of a positive relation between spatial crowding and negative emotions, in magnitude, direction and statistical significance (Table 2). Similarly, it was expected that spatial crowding would dampen positive emotions such as joy and excitement. However, our results suggest otherwise. This finding highlights the need for more qualitative explanations as why and under what conditions spatial crowding could contribute to positive emotions. Analysis of prior studies suggests that human crowding could reduce the perceptions of negative emotions given the contact and stimulation obtained from other people in the store. Alternatively, the arousal from others in the environment could also contribute to a positive impact of human crowding on positive emotions. On the other hand, if the presence of others prevents goal attainment, human crowding could enhance negative emotions (or dampen positive emotions). Our analysis, however, reveals that human crowding has a positive effect on both positive and negative emotions (Table 2). The positive relationship between human crowding and negative emotions deserves closer examination in future. It is possible that the arousal caused by others in a store environment could be context-dependent and interpreted either positively or negatively (Mandler 1964). It could also be that while the presence of others may be evaluated positively, the physical closeness of others in a given space may contribute to enhanced stress. Future research could attempt to understand the impacts of human crowding on emotions in different contextual settings.

Prior research has argued that customers make inferences about the crowding they encounter in stores and evaluate stores based on such inferences (Tse et al. 2002). Such evaluations could be positive or negative. Our analysis found that human crowding had a significant and positive impact on store evaluations. Most likely, stores with higher number of customers may indicate higher quality merchandise and/or services. Spatial crowding had a negative effect, albeit we did not find it to be statistically significant. However, this result 
confirms the perspective that spatial crowding may lead to the store to be evaluated as of “discount store image" (Lee et al. 2011, p. 133). Future research could examine in-depth how spatial crowding contributes to store image perceptions and store evaluations.

\section{Mediator Tests and the Power of an Integrative Framework}

While prior studies have employed various theoretical perspectives, rationales, and constructs in empirical research on the effects of crowding, our integrative model not only provides a comparative test of these prior approaches but also gives insights that are not possible with single-theory approaches. Mediation of various constructs proposed by the different theories are depicted in Models 2, 3 and 4 (Figure 1). Results of structural equation modeling confirm the mediation of perceived control, positive and negative emotions, and store evaluations in the relation between human and spatial crowding and actual behavior and behavioral intentions (Table 3). The results also suggest that the indirect effects on intentions were much greater than on actual behavior suggesting that mediation is quite relevant for the impacts on human and spatial crowding on intentions (Table 4). Further, perceived control is a stronger mediator for spatial crowding than human crowding.

Moreover, we used structural equation modeling to assess the developed integrative framework which builds on several theories (Table 3). First, our meta-analysis reveals that, in line with theoretical predictions of coping theories, customers engage in coping under both forms of crowding, ostensibly to reduce their negative effects. In line with descriptive results, one revealing aspect is that human crowding positively influences actual behavior, whereas spatial crowding positively impacts intentions (Model 5, Table 3). The positive impacts of human crowding have been explained with reference to optimal social contact theory, which argues that customers sometimes seek the presence of other shoppers (Eroglu et al. 2005). On the other hand, the positive impacts of spatial crowding on intentions may be due to expectancy-disconfirmation theory (e.g., Bitner 1992); spatially crowded stores have an 
appeal to customers for some other reasons (e.g., related to merchandise, low prices) and scholars should use qualitative research to examine these underlying reasons. Second, while prior researchers have argued that crowding negatively impacts a customer's perceived control (Dion 2004), our meta-analysis reveals that mainly spatial crowding has this impact. Human crowding seems to restrict the shopper's freedom less than spatial crowding does, as also emphasized by Rompay et al. (2008). Third, in line with the Mehrabian-Russell model, the results suggest that both human and spatial crowding trigger positive as well as negative emotions, thereby providing evidence of their ambivalent nature. Human crowding perceptions enhance positive emotions and also stress (Kruse 1986); again, we find that spatial crowding can also elicit positive emotions. Fourth, our meta-analysis clarifies that perceptions of human crowding contribute to more favorable evaluations of the store, whereas spatial crowding produces negative evaluations as suggested by inference theory. Finally, the integrative model brings out the interrelationships among constructs suggested by the various theoretical perspectives. For instance, control perceptions impact customers' emotions, which, in turn, influence customers' inferences about retailers.

\section{Moderating Impacts of Human and Spatial Crowding}

This meta-study assessed the impact of several moderators (Table 5). First, we find that the positive effects of human crowding become stronger in hedonic retail settings, possibly because the presence of others in such contexts is a source of fun and enjoyment or even an evidence of quality. For spatial crowding, we observe mixed results. While spatial crowding has a negative effect on intentions in hedonic setting, in line with theory, its effect in utilitarian context is positive. It may well be possible that in utilitarian contexts, spatial crowding does not hinder task achievement. Future research could closely examine the interplay of customer shopping goals and spatial crowding in utilitarian contexts. Second, as predicted, spatial crowding has a weaker negative effect on satisfaction in the context of 
single stores as compared to agglomerations. However, spatial crowding's effect on intentions was found to be positive in the context of agglomerations. It is possible that spatially restricted malls lead to perceptions of efficiency in shopping and therefore, customers may be more likely to return to such agglomerations. While we did not hypothesize the effects of this moderation for human crowding, we did find some interesting effects. For example, human crowding has a stronger positive effect on intentions in the context of agglomerations as compared to single stores; however, this effect was negative on satisfaction and behavior in the context of agglomerations. Customer expectations and inferences may be of relevance here. For example, shoppers do expect malls to be crowded; however, typically navigation through the mall is often facilitated by the mall layout. When this is hindered by the presence of more people, it may be that such human crowding runs afoul of expectations, contributing to negative outcomes. Future research may test the impacts of different layouts, not only store layouts but also mall layouts on the impacts of spatial and human crowding on customer outcomes. Third, while prior research has pointed to employee support as mitigating the negative effects of human crowding, our results were contrary to what was predicted from prior literature. Specifically, we find that human crowding has a negative effect on satisfaction in the context of employee support (rather than positive). Moreover, the negative effects of spatial crowding were stronger in the context of employee support. Some prior research on the interactions of employees and customers suggest different factors that could be examined in future research. For example, employees' emotional expressions and behaviors as well as their control over the interaction may affect customer evaluations. Future research could more explicitly model various employee attributes and behaviors that may impact customer evaluations when confronted with crowded situations. Fourth, in terms of customer type as well, there are several interesting findings. While the positive effect of human crowding on satisfaction is evident in the context 
of existing customers, this effect is negative for new customers. However, we find the human crowding has stronger positive effects on the other outcomes for new customer rather than as predicted, for the existing customers. We also find some moderating effects for spatial crowding such as the negative effects of spatial crowding on satisfaction being stronger for new than existing customers. It is quite possible that crowding impedes the full sensory experience for new customers; existing customers may be quite aware and take for granted the various sensory stimulations in the atmosphere. Future research should therefore consider how human and spatial crowding impact customer outcomes for different customer types. Fifth, our testing of the environment as cooperative or competitive reveals various new insights. As predicted, human crowding has a stronger positive effect on behavioral intentions in cooperative environments as compared to competitive environments. However, an opposite effect was found for satisfaction; the positive effect of human crowding on satisfaction was stronger in competitive environments. One possible explanation could be the sense of "winning" in the presence of others, such as securing a bargain on a limited quantity item in a crowded store. Finally, in terms of study characteristics, some differences were observed for study year, research design, and sampling approach. Later studies found stronger positive effects for human crowding and stronger negative effects for spatial crowding. Also, the effects are more pronounced in surveys than in experiments. The above findings indicate the importance of various moderators in the study of the effects of crowding, as well as the importance of designing rigorous studies that will detect all effects. Future studies should actively explore the roles and impacts of such moderators, along with the various other future research questions that are suggested by our meta-analysis, as summarized in Table 7.

[Insert Table 7 here]

\section{Managerial Implications}


In a competitive multi-channel environment where many brick-and-mortar retailers are rethinking their business models, and even survival strategies, the negative impacts of crowding appear to be one more reason for loss of customer patronage and future sales. In addition, many aspects are beyond the control of the retailer since crowding perceptions may vary not only according to individuals, but also, as our meta-analysis reveals, according to various situations and circumstances. The clear distinction between human and spatial crowding, as well as their differential impacts, afford retailers an opportunity to craft strategies to minimize the negative impacts of crowding. First, our findings suggest that managers must understand the different impacts of both crowding types. Perceptions of human crowding can be only somewhat influenced by managers through strategies that affect demand on different days and times. However, managers may be better able to control and manage how their retail space affects perceptions of spatial crowding and devise strategies that may alleviate such perceptions. For example, retailers could focus on the architectural aspects of stores and, where possible, provide more space and reduce crowding where it is most likely to have adverse impacts, such as at checkout counters, customer service desks, and gift-wrapping areas (Machleit et al. 1994). Second, the finding that human crowding is not perceived as negative per se by customers may be good news for retailers and service providers, such as bars and restaurants, whose businesses obtain a positive image because of the presence of several people at the same time. Managers should also examine if their retail or service setting is perceived as hedonic, and whether attracting more customers into their store would have positive impacts on customer responses given prior perceptions of the store image and merchandise. Third, managers should acknowledge that most crowding effects are context-dependent. Some retail types, such as those with predominantly utilitarian offerings (e.g., grocery stores) benefit less from human crowding. Managers of these stores need to manage demand and supply better so as to manage crowding. Fourth, managers should 
consider the customer motivations to visit a specific retail format. Shoppers are less dissatisfied with spatial restrictions in single stores than in malls. Managers of malls should take actions to eliminate factors that restrict shopper ease and convenience of access and freedom of movement. Fifth, retailers have to understand that employee support may not be very useful to help customers cope with the negative feelings associated with spatial crowding. However, greater use of in-store technologies (self-service checkouts, robotic assistance) to ease checkout and exiting the store may alleviate crowding perceptions. Sixth, new customers were found to react more negatively to human and spatial crowding in terms of shopping satisfaction. Thus, managers should provide new customers with some indication of when to visit the store. For example, they could solicit new customers for visits on days or at times when human crowding may be perceived to be lower (based on prior analysis). They may also explain the store layout to these customers, and indicate where to find the merchandise and exits to address concerns about spatial restrictions. Finally, since the impacts of crowding on some outcomes are affected by whether the environment is perceived as competitive or cooperative, retailers could encourage greater interactions between customers to create a more cooperative environment. An example of the latter is seating arrangements in neighborhood coffee shops and diners where proximity may foster a cooperative environment.

\section{Limitations and Further Research}

Like most research, the present meta-analysis has limitations that must be acknowledged so that future studies are better guided. First, some analyses were limited by data availability since not all mediators, moderators, and outcome variables find sufficient representation in prior empirical studies. Second, a future meta-study could examine the antecedents of crowding. For example, given the relationships between density and crowding, future research in the context of retailing could examine the relationship between social and 
spatial density and the two types of crowding. Third, most crowding studies have used measurements that do not differentiate between affective and cognitive crowding dimensions. Future studies should compare the differences between the affective and cognitive evaluations of human and spatial crowding (Dion 2004). It may well be that affective evaluation differs from cognitive evaluation. Fourth, this meta-analysis examines crowding based on studies conducted primarily in the U.S., Europe, and Asia. Studying crowding in new and emerging markets where modern retailing and shopping malls are only now becoming a reality would help to assess the generalizability of the results to various contexts. Fifth, variations in effect sizes remained even after accounting for contextual and methodological factors, suggesting that, as more studies are conducted, further moderators should be examined. Future studies should test moderators such as risk orientation of the shopper, or shopping task complexity.

\section{REFERENCES}

Allport, G.W. (1954). The nature of prejudice. Reading, MA: Addison Wesley.

Altman, Irwin and Martin M. Chemers (1984). Culture and Environment, Cambridge, England: Cambridge University

Alwin, D. F., and R. M. Hauser (1975), "The decomposition of effects in path analysis,” American Sociological Review, 40(1), 37-47.

Baldassare, M. (1978), "Human spatial behavior," Annual Review of Sociology, 4(1), 29-56.

Baker, J., M. Levy, and D. Grewal (1992), “An experimental approach to making retail store environmental decisions," Journal of Retailing, 68(4), 445-460.

Baker, J., D. Grewal, and A. Parasuraman (1994), "The influence of store environment on quality inference and store image," Journal of Academy of Marketing Science, 22(4), 328-339.

Baker, J., A. Parasuraman, D. Grewal, and G. B. Voss (2002), "The influence of multiple store environment cues on perceived merchandise value and patronage intentions," Journal of Marketing, 66(2), 120-141.

Baker, J., and K. L. Wakefield (2012), "How consumer shopping orientation influences perceived crowding, excitement, and stress at the mall," Journal of the Academy of Marketing Science, 40(6), 791-806.

Bitner, M. J. (1992), "Servicescapes: The impact of physical surroundings on customers and employees," Journal of Marketing, 56(2), 57-71.

Bloch, P. H., N. M. Ridgway, and S. A. Dawson (1994), "The shopping mall as consumer habitat," Journal of Retailing, 70(1), 23-42.

Brehm, J. W. (1989), "Psychological reactance: Theory and applications," Advances in Consumer Research, 16, 72-75.

Das, G., and G. Varshneya (2017), "Consumer emotions: Determinants and outcomes in a shopping mall," Journal of Retailing and Consumer Services, 38, 177-185.

Dion, D. (1999), “A theoretical and empirical study of retail crowding," European Advances in Consumer Research, 4, 51-57.

Dion, D. (2004). "Personal control and coping with retail crowding," International Journal of Service Industry Management, 15(3), 250-263. 
Donovan, R. J., J.R. Rossiter, G. Marcoolyn, and A. Nesdale (1994), "Store atmosphere and purchasing behavior," Journal of Retailing, 70(3), 283-294.

Eroglu, S. A., and G. D. Harrell (1986), "Retail crowding: Theoretical and strategic implications," Journal of Retailing, 62(4), 346-363.

Eroglu, S.A., and K.A. Machleit (1990), “An empirical study of retail crowding: antecedents and consequences," Journal of Retailing, 66(2), 201-221.

Eroglu, S.A., K.A. Machleit, and T.F. Barr (2005), "Perceived retail crowding and shopping satisfaction: The role of shopping values," Journal of Business Research, 58(8), 1146-1153.

Gelbrich, K., and B. Sattler (2014), “Anxiety, crowding, and time pressure in public self-service technology acceptance," Journal of Services Marketing, 28(1), 82-94.

Geyskens, I., R. Krishnan, J. B. E. Steenkamp, and P. V. Cunha (2009), “A review and evaluation of metaanalysis practices in management research," Journal of Management, 35(2), 393-419.

Grewal, D., J. Baker, M. Levy, and G.B. Voss (2003), "The effects of wait expectations and store atmosphere evaluations on patronage intentions in service-intensive retail stores," Journal of Retailing, 79(4), 259-268.

Grewal, D., N. Puccinelli, and K. B. Monroe (2018), "Meta-analysis: integrating accumulated knowledge," Journal of the Academy of Marketing Science, 46(1), 1-22.

Harrell, G. D., M. D. Hutt, and J. C. Anderson (1980), "Path analysis of buyer behavior under conditions of crowding," Journal of Marketing Research, 17(1), 45-51.

Helson, H. (1964). Adaptation-level theory: an experimental and systematic approach to behavior. New York: Harper \& Row.

Hortaçsu, A., and C. Syverson (2015), "The ongoing evolution of US retail: A format tug-of-war," Journal of Economic Perspectives, 29(4), 89-112.

$\mathrm{Hu}$, H., and C. R. Jasper (2006), "Social cues in the store environment and their impact on store image," International Journal of Retail \& Distribution Management, 34(1), 25-48.

Hui, M. K., and J. E. Bateson (1991), "Perceived control and the effects of crowding and consumer choice on the service experience," Journal of Consumer Research, 18(2), 174-184.

Hunter, J. E., and F. L. Schmidt (2004), Methods of meta-analysis: Correcting error and bias in research findings. Thousand Oaks, CA: Sage Publications.

Jöreskog, K. G., U. H. Olsson, and F. Y. Wallentin (2016). Multivariate analysis with LISREL. New York: Springer.

Kim, D., C. K. Lee, and M. J. Sirgy (2016), "Examining the differential impact of human crowding versus spatial crowding on visitor satisfaction at a festival," Journal of Travel \& Tourism Marketing, 33(3), 293-312.

Kim, J. H., and R. Runyan (2011). "Where did all the benches go?," International Journal of Retail \& Distribution Management, 39(2), 130-143.

Kruse, L. (1986), “Conceptions of crowds and crowding,” in: C.R. Graumann and S. Moscovici (eds.). Changing conceptions of crowd mind and behavior. Springer, New York, NY. 117-142.

Lazarus, R. S., and S. Folkman (1984), Stress, Appraisal, and Coping. New York: Springer.

Lee, S., J. O. Kim, and J. G. Li (2011), "Impacts of store crowding on shopping behavior and store image," Journal of Asian Architecture and Building Engineering, 10(1), 133-140.

Li, J.-G.T., J.-O. Kim, and S.Y. Lee (2009), “An empirical examination of perceived retail crowding, emotions, and retail outcomes," Service Industries Journal, 29(5), 635-652.

Loo, C. (1975), "The psychological study of crowding: Some historical roots and conceptual developments," American Behavioral Scientist, 18(6), 826-842.

Machleit, K. A., J. J. Kellaris, and S. A. Eroglu (1994), "Human vs. spatial dimensions of crowding perceptions in retail environments: A note on their measurement and effect on shopper satisfaction," Marketing Letters, 5(2), 183-194.

Machleit, K. A., S. A. Eroglu, and S. P. Mantel (2000), "Perceived retail crowding and shopping satisfaction: what modifies this relationship?," Journal of Consumer Psychology, 9(1), 29-42.

Madzharov, A. V., L. G. Block, and M. Morrin (2015), "The cool scent of power: Effects of ambient scent on consumer preferences and choice behavior," Journal of Marketing, 79(1), 83-96.

Mandler, G. (1964). The interruption of behavior. In D. Levine (Ed.), Nebraska Symposium on Motivation (Vol. 12). Lincoln: University of Nebraska Press, 1964.

Mattila, A. (1998), "An examination of consumers' use of heuristic cues in making satisfaction judgments," Psychology \& Marketing, 15(5), 477-501. 
Mattila, A. S., and J. Wirtz (2008), "The role of store environmental stimulation and social factors on impulse purchasing," Journal of Services Marketing, 22(7), 562-567.

Mehrabian, A., and J. A. Russell (1974). An approach to environmental psychology. Cambridge: MIT.

Mehta, R. (2013), "Understanding perceived retail crowding: A critical review and research agenda," Journal of Retailing and Consumer Services, 20(6), 642-649.

Menon, S. and B. Kahn (2002), "Cross-category effects of induced arousal and pleasure on the Internet shopping experience," Journal of Retailing, 78(1), 31-40

Noone, B. M., and A. S. Mattila (2009), "Consumer reaction to crowding for extended service encounters," Managing Service Quality: An International Journal, 19(1), 31-41.

O'Guinn, T. C., R. J. Tanner, and A. Maeng (2015), "Turning to space: social density, social class, and the value of things in stores," Journal of Consumer Research, 42(2), 196-213.

Palmatier, R. W., Dant, R. P., \& Grewal, D. (2007), „A comparative longitudinal analysis of theoretical perspectives of interorganizational relationship performance," Journal of Marketing, 71(4), 172-194.

Peterson, R. A., and S.P. Brown (2005), "On the use of beta coefficients in meta-analysis," Journal of Applied Psychology, 90(1), 175-181.

Pettigrew, T.F. (1998), "Intergroup contact theory," American Review of Psychology, 49(1), 65-85.

Pettigrew, T.F., and L.R. Tropp (2006), "A meta-analytic test of intergroup contact theory," Journal of Personality and Social Psychology, 90(5), 751-783.

Pettigrew, T.F., L.R. Tropp, U. Wagner, and O. Christ (2011), "Recent advances in intergroup theory," International Journal of Intercultural Relations, 35(3), 271-280.

Pons, F. (2004). "Is too few really better than too many?" Development of the perceived human concentration scale and its impact on the service experience. Dissertation, Concordia University.

Pons, F., M. M. Laroche, and M. Mourali (2006), "Consumer reactions to crowded retail settings: Crosscultural differences between North American and the Middle East," Psychology and Marketing, 23(7), $555-572$.

Pons, F., M. Mourali, and M. Giroux (2014), “The density-satisfaction relationship revisited," Journal of Retailing and Consumer Services, 21(1), 54-60.

Rafaeli, A. (1989), "When cashiers meet customers: An analysis of the role of supermarket cashiers," Academy of Management Journal, 32(2), 245-273.

Rafaeli, A. and R. I. Sutton (1990), "Busy stores and demanding customers: How do they affect the display of positive emotion?" Academy of Management Journal, 33(3), 623-637.

Rosenthal, R. (1979), "The file drawer problem and tolerance for null results," Psychological Bulletin, 86(3), 638-641.

Schmidt, D. E., and J. P. Keating (1979), "Human crowding and personal control: An integration of the research," Psychological Bulletin, 86(4), 680-700.

Shelby, B., J. J. Vaske, and T. A. Heberlein (1989), "Comparative analysis of crowding in multiple locations: Results from fifteen years of research," Leisure Sciences, 11(4), 269-291.

Sinha, S.P. and N. Mukherjee (1996), "The effect of perceived cooperation in personal space requirements," Journal of Social Psychology, 136(5), 655-657.

Stokols, D. (1972a), "A social-psychological model of human crowding phenomena," Journal of the American Institute of Planners, 38(2), 72-83.

Stokols, D. (1972b), "On the distinction between density and crowding: some implications for future research," Psychological Review, 79(3), 275-277.

Stokols, D. (1976), "The experience of crowding in primary and secondary environments," Environment and Behavior, 8(1), 49-86.

Tse, A.C.B., L. Sin, and F.H.K. Yim (2002), "How a crowded restaurant affects consumers' attribution behavior," International Journal of Hospitality Management, 21(4), 449-454.

van Rompay, T. J. L., M. Galetzka, A. T. Pruyn, and J. M. Garcia (2008), "Human and spatial dimensions of retail density: revisiting the role of perceived control," Psychology \& Marketing, 25(4), 319-335.

Verhoef, P. C., K. N. Lemon, A. Parasuraman, A. Roggeveen, M. Tsiros, and L. A. Schlesinger (2009), "Customer experience creation: Determinants, dynamics and management strategies," Journal of Retailing, 85(1), 31-41.

Webb, W. M., and S. Worchel (1993), "Prior experience and expectation in the context of crowding," Journal of Personality and Social Psychology, 65(3), 512-521

Worchel, S., and C. Teddlie (1976), "The experience of crowding: A two-factor theory," Journal of Personality and Social Psychology, 34(1), 30-40. 


\section{TABLE 1: THEORIES AND MEASUREMENTS IN CROWDING RESEARCH}

Panel A: Theories and Models used in Crowding Research

\begin{tabular}{lll}
\hline Theory & Frequency & Percent \\
\hline Mehrabian-Russell model & 14 & $30 \%$ \\
Perceived control model & 13 & $28 \%$ \\
Information overload theory & 13 & $28 \%$ \\
Inference theory & 9 & $19 \%$ \\
Arousal theory & 8 & $17 \%$ \\
Approach-avoidance theory & 7 & $15 \%$ \\
Behavioral constraint theory & 7 & $15 \%$ \\
Goal attainment theory & 6 & $13 \%$ \\
Adaptation strategy/coping theory & 5 & $11 \%$ \\
Manning theory & 5 & $11 \%$ \\
Expectancy-disconfirmation theory & 3 & $6 \%$ \\
Reactance theory & 3 & $6 \%$ \\
Servicescape model & 3 & $6 \%$ \\
Other theories & 16 & $34 \%$ \\
No theory & 12 & $9 \%$ \\
\hline Total & $\mathbf{4 7}$ studies & $\mathbf{2 4 7 \%}$ \\
\hline
\end{tabular}

Note: The studies collected for the meta-analysis were searched for this overview. For most unpublished studies, only the effect sizes are available and no theory can be extracted. Not all of the identified theories were formally tested in each study. Sometimes authors refer to them when describing the crowding construct and its effects. The table only displays theories which were mentioned at least three times.

Panel B: Measurements used in Crowding Research

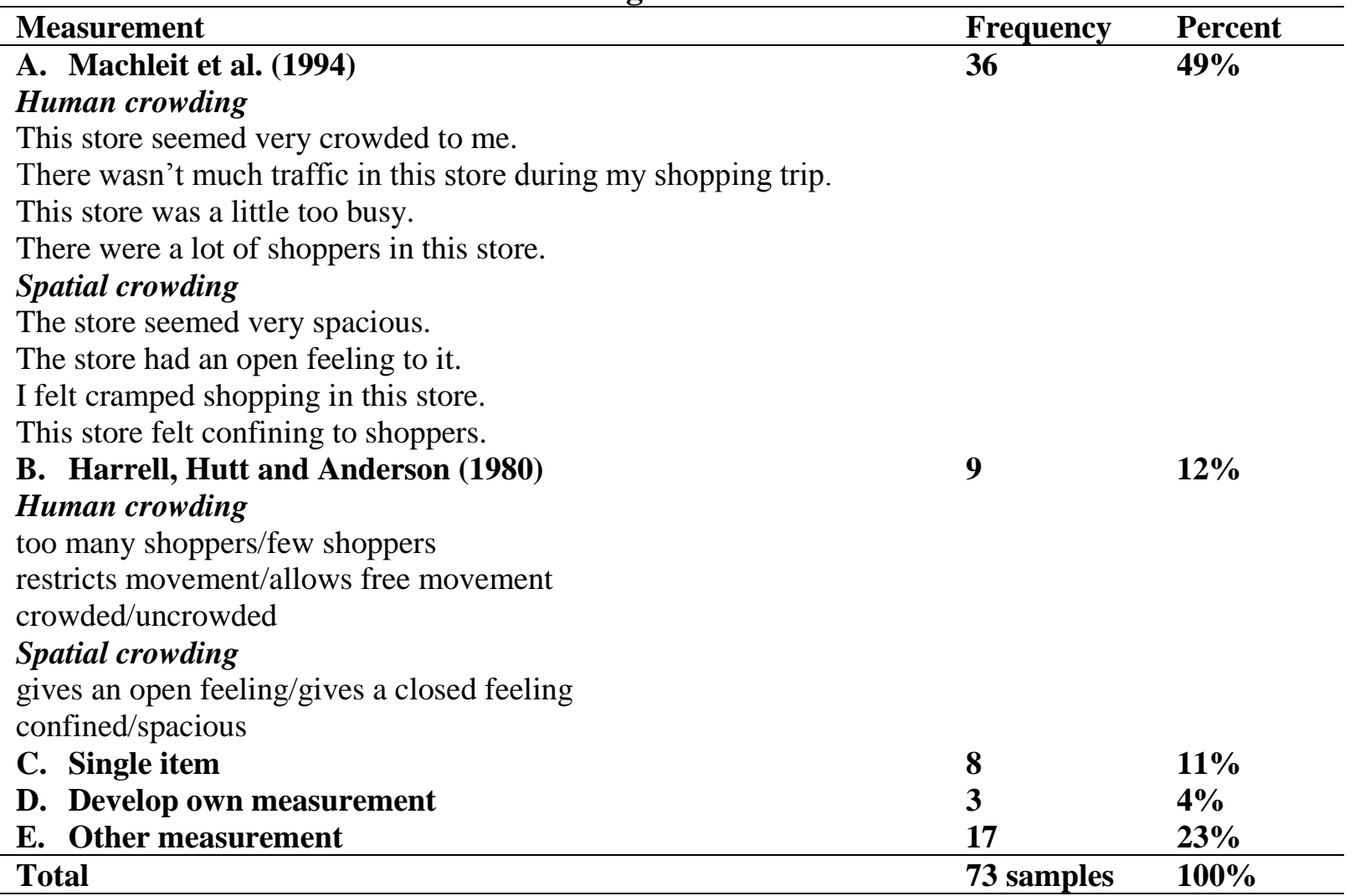

Note: The Harrell et al. (1980) measures are described in Machleit et al. (1994) and also included an item whether "customers can move at their own pace". This item loaded on both crowding dimensions and was removed from the scale. Also, while restrictions in movement were initially grouped into human crowding, the scale item loaded on the factor interpreted to be spatial crowding (see Table 1 in Machleit et al. 1994). The measurements in the meta-study were classified based on the used items. 
TABLE 2

DESCRIPTIVE RESULTS AND CORRELATIONS OF CROWDING WITH OUTCOME VARIABLES

\begin{tabular}{|c|c|c|c|c|c|c|c|c|c|c|c|c|c|c|c|c|c|c|}
\hline DV & $\mathbf{k}$ & $\mathbf{N}$ & $\mathbf{r}$ & $\mathbf{r W}$ & re & Min rc & Max rc & rc $_{\mathrm{SO}}$ & $\mathbf{r c}_{\mathrm{EO}}$ & BESD & SD & $\mathbf{C I}_{\text {low }}$ & $\mathbf{C I}_{\text {high }}$ & $\mathbf{C R}_{\text {low }}$ & $\mathbf{C R}_{\text {high }}$ & $\mathbf{Q}$ & FSN & TOL \\
\hline Human crowding Satisfaction & 25 & 6,084 & .02 & .05 & .06 & -.59 & 67 & .09 & .05 & $13 \%$ & .23 & -.04 & .15 & -.24 & .35 & $279 *$ & - & - \\
\hline Human crowding Behavioral intentions & 21 & 4,038 & .06 & .06 & .06 & -.49 & .85 & .06 & .04 & $13 \%$ & .24 & -.04 & .17 & -.24 & .37 & $208 *$ & - & - \\
\hline Human crowding Actual behavior & 13 & 3,819 & .17 & .05 & .06 & -.08 & .58 & $.10 *$ & .06 & $13 \%$ & .13 & -.02 & .14 & -.11 & .22 & $64 *$ & - & - \\
\hline Human crowding Perceived control & 10 & 1,989 & -.06 & -.10 & -.12 & -.66 & .62 & -.02 & $-.14 *$ & $-21 \%$ & .23 & -.27 & .03 & -.42 & .18 & $91 *$ & - & - \\
\hline Human crowding Positive emotions & 26 & 5,891 & .02 & .06 & .07 & -.77 & .95 & .09 & .03 & $15 \%$ & .38 & -.08 & .22 & -.42 & .56 & $706 *$ & - & - \\
\hline Human crowding Negative emotion & 15 & 3,636 & .25 & .29 & $.32 *$ & -.16 & .69 & $.29 *$ & $.32 *$ & $94 \%$ & .16 & .23 & .41 & .12 & .53 & $85^{*}$ & 1,098 & 85 \\
\hline Human crowding Store evaluation & 24 & 7,205 & .12 & .14 & $.16^{*}$ & -.30 & .57 & $.15^{*}$ & $.16^{*}$ & $38 \%$ & .18 & .09 & .24 & -.07 & .39 & $207 *$ & 852 & 135 \\
\hline Human crowding Spatial crowding & 18 & 4,232 & .22 & .35 & $.42 *$ & -.75 & 74 & $.38 *$ & $.44^{*}$ & $145 \%$ & .27 & .29 & .55 & .08 & .76 & $246^{*}$ & 1,988 & 100 \\
\hline Spatial crowding Satisfaction & 17 & 3,812 & -.26 & -.21 & $-.23 *$ & -.60 & .45 & $-.18 *$ & $-.22 *$ & $-37 \%$ & .35 & -.40 & -.06 & -.68 & .22 & $374 *$ & 1,114 & 95 \\
\hline Spatial crowding Behavioral intentions & 14 & 2,490 & -.12 & -.03 & -.02 & -.60 & .35 & -.10 & -.01 & $-4 \%$ & .27 & -.17 & .13 & -.37 & .33 & $171 *$ & - & - \\
\hline Spatial crowding Actual behavior & 10 & 3,312 & -.09 & -.05 & $-.05 *$ & -.41 & .09 & $-.09 *$ & $-.05 *$ & $-10 \%$ & .06 & -.11 & -.00 & -.13 & .03 & $21 *$ & 23 & 60 \\
\hline Spatial crowding Perceived control & 12 & 3,310 & -.28 & -.24 & $-.28 *$ & -.68 & .02 & $-.28 *$ & $-.27 *$ & $-44 \%$ & .12 & -.36 & -.20 & -.43 & -.13 & $43 *$ & 704 & 70 \\
\hline Spatial crowding Positive emotions & 19 & 4,851 & -.07 & .05 & .07 & -.63 & 1.09 & .12 & .08 & $15 \%$ & .43 & -.13 & .26 & -.48 & 61 & $697 *$ & - & - \\
\hline Spatial crowding Negative emotion & 12 & 3,328 & .21 & .31 & $.36^{*}$ & -.11 & .73 & $.32 *$ & $.35^{*}$ & $113 \%$ & .18 & .25 & .46 & .12 & .59 & $94 *$ & 840 & 70 \\
\hline Spatial crowding Store evaluation & 14 & 4,210 & -.19 & -.12 & -.12 & -.54 & .33 & -.06 & -.12 & $-21 \%$ & .26 & -.26 & .02 & -.46 & .21 & $243 *$ & - & - \\
\hline
\end{tabular}

$\mathrm{k}=$ number of effect sizes; $\mathrm{N}=$ cumulative sample size; $\mathrm{r}=$ observed average correlation; $\mathrm{rw}=$ sample-weighted average correlation; rc=sample-weighted reliability adjusted average correlation; $\mathrm{rcso}=\mathrm{rc}$ without sample size outliers; $\mathrm{rc}_{\mathrm{EO}}=\mathrm{rc}$ without effect size outliers; $\mathrm{CI}=95 \%$-confidence interval; $\mathrm{CR}=80 \%$ credibility interval; $\mathrm{Q}=\mathrm{Q}$ statistic;

FSN=fail-safe N; TOL=tolerance level for FSN. $*<.05$-level. 
TABLE 3

RESULTS OF THE STRUCTURAL EQUATION MODEL

\begin{tabular}{|c|c|c|c|c|c|c|c|c|c|c|c|}
\hline \multirow[b]{2}{*}{ DV } & \multirow[b]{2}{*}{ IV } & \multicolumn{2}{|c|}{$\begin{array}{c}\text { Model 1: } \\
\text { Coping theory }\end{array}$} & \multicolumn{2}{|c|}{$\begin{array}{c}\text { Model 2: } \\
\text { Control model }\end{array}$} & \multicolumn{2}{|c|}{$\begin{array}{c}\text { Model 3: } \\
\text { Emotional response }\end{array}$} & \multicolumn{2}{|c|}{$\begin{array}{c}\text { Model 4: } \\
\text { Inference theory }\end{array}$} & \multicolumn{2}{|c|}{$\begin{array}{c}\text { Model 5: } \\
\text { Integrated model }\end{array}$} \\
\hline & & B & $\mathbf{R}^{2}$ & B & $\mathbf{R}^{2}$ & B & $\mathbf{R}^{2}$ & B & $\mathbf{R}^{2}$ & B & $\mathbf{R}^{2}$ \\
\hline \multirow[t]{7}{*}{ Actual behavior } & Human crowding & $.10^{*}$ & $1.10 \%$ & - & $1.00 \%$ & - & $3.70 \%$ & - & $4.80 \%$ & $.08 *$ & $6.10 \%$ \\
\hline & Spatial crowding & $-.10 *$ & & - & & - & & - & & $-.09 *$ & \\
\hline & Behavioral intentions & - & & - & & - & & - & & $.05 *$ & \\
\hline & Perceived control & - & & $.06^{*}$ & & - & & - & & $-.08 *$ & \\
\hline & Positive emotions & - & & - & & $.18 *$ & & - & & $.17 *$ & \\
\hline & Negative emotion & - & & - & & $-.06 *$ & & - & & -.04 & \\
\hline & Store evaluation & - & & - & & - & & $.22 *$ & & $.07 *$ & \\
\hline \multirow[t]{6}{*}{ Behavioral intentions } & Human crowding & $.07 *$ & $1.00 \%$ & - & $5.80 \%$ & - & $16.60 \%$ & - & $24.00 \%$ & $-.13 *$ & $31.40 \%$ \\
\hline & Spatial crowding & $-.05 *$ & & - & & - & & - & & $.10 *$ & \\
\hline & Perceived control & - & & $.24 *$ & & - & & - & & $.26^{*}$ & \\
\hline & Positive emotions & - & & - & & $.41 *$ & & - & & -.05 & \\
\hline & Negative emotion & - & & - & & -.03 & & - & & $.23 *$ & \\
\hline & Store evaluation & - & & - & & - & & $.49^{*}$ & & $.61 *$ & \\
\hline \multirow[t]{5}{*}{ Store evaluation } & Human crowding & - & & - & & - & & $.26^{*}$ & $6.80 \%$ & $.30 *$ & $59.80 \%$ \\
\hline & Spatial crowding & - & & - & & - & & $-.23^{*}$ & & $-.27 *$ & \\
\hline & Perceived control & - & & - & & - & & - & & $-.43 *$ & \\
\hline & Positive emotions & - & & - & & - & & - & & $.75^{*}$ & \\
\hline & Negative emotion & - & & - & & - & & - & & $-.41 *$ & \\
\hline \multirow[t]{3}{*}{ Negative emotion } & Human crowding & - & & - & & $.21 *$ & $16.40 \%$ & - & & $.21 *$ & $18.20 \%$ \\
\hline & Spatial crowding & - & & - & & $.27 *$ & & - & & $.24 *$ & \\
\hline & Perceived control & - & & - & & - & & - & & $-.14 *$ & \\
\hline \multirow[t]{3}{*}{ Positive emotions } & Human crowding & - & & - & & $.05^{*}$ & $1.00 \%$ & - & & $.05^{*}$ & $35.90 \%$ \\
\hline & Spatial crowding & - & & - & & $.05^{*}$ & & - & & $.22 *$ & \\
\hline & Perceived control & - & & - & & - & & - & & $.62 *$ & \\
\hline \multirow[t]{2}{*}{ Perceived control } & Human crowding & - & & .00 & $7.80 \%$ & - & & - & & .00 & $7.80 \%$ \\
\hline & Spatial crowding & - & & $-.28 *$ & & - & & - & & $-.28 *$ & \\
\hline \multirow[t]{5}{*}{ Model fit } & $\chi^{2}(\mathrm{df})$ & $35(1)$ & & $62(5)$ & & $78(6)$ & & $18(5)$ & & $11(1)$ & \\
\hline & CFI & .921 & & .918 & & .941 & & .988 & & .998 & \\
\hline & GFI & .991 & & .987 & & .986 & & .996 & & .999 & \\
\hline & RMR & .042 & & .045 & & .040 & & .017 & & .014 & \\
\hline & SRMR & .042 & & .045 & & .040 & & .017 & & .014 & \\
\hline
\end{tabular}


TABLE 4

DIRECT, INDIRECT, AND TOTAL EFFECTS

\begin{tabular}{|c|c|c|c|c|c|}
\hline DV & IV & Direct & Indirect & Total & rel. Imp. \\
\hline \multirow[t]{7}{*}{ Actual behavior } & Behavioral intentions & $.05^{*}$ & - & $.05^{*}$ & $0 \%$ \\
\hline & Human crowding & $.08 *$ & .02 & $.10 *$ & $22 \%$ \\
\hline & Spatial crowding & $-.09 *$ & .00 & $-.09 *$ & $1 \%$ \\
\hline & Perceived control & $-.08 *$ & $.13^{*}$ & $.05^{*}$ & $62 \%$ \\
\hline & Positive emotions & $.17 *$ & $.07 *$ & $.25^{*}$ & $29 \%$ \\
\hline & Negative emotion & -.04 & $-.03 *$ & $-.07 *$ & $42 \%$ \\
\hline & Store evaluation & $.07 *$ & $.03 *$ & $.10 *$ & $28 \%$ \\
\hline \multirow[t]{6}{*}{ Behavioral intentions } & Human crowding & $-.13 *$ & $.20 *$ & $.07 *$ & $61 \%$ \\
\hline & Spatial crowding & $.10^{*}$ & $-.15^{*}$ & $-.05^{*}$ & $60 \%$ \\
\hline & Perceived control & $.26^{*}$ & .00 & $.26^{*}$ & $1 \%$ \\
\hline & Positive emotions & -.05 & $.46^{*}$ & $.41 *$ & $91 \%$ \\
\hline & Negative emotion & $.23 *$ & $-.25 *$ & -.02 & $53 \%$ \\
\hline & Store evaluation & $.61 *$ & - & $.61 *$ & - \\
\hline \multirow[t]{5}{*}{ Store evaluation } & Human crowding & $.30 *$ & $-.05 *$ & $.26^{*}$ & $13 \%$ \\
\hline & Spatial crowding & $-.27 *$ & $.04 *$ & $-.23^{*}$ & $14 \%$ \\
\hline & Perceived control & $-.43 *$ & $.52 *$ & $.09 *$ & $55 \%$ \\
\hline & Positive emotions & $.75^{*}$ & - & $.75^{*}$ & - \\
\hline & Negative emotion & $-.41 *$ & - & $-.41 *$ & - \\
\hline \multirow[t]{3}{*}{ Negative emotion } & Human crowding & $.21 *$ & .00 & $.21 *$ & $0 \%$ \\
\hline & Spatial crowding & $.24 *$ & $.04 *$ & $.27 *$ & $14 \%$ \\
\hline & Perceived control & $-.14 *$ & - & $-.14^{*}$ & - \\
\hline \multirow[t]{3}{*}{ Positive emotions } & Human crowding & $.05 *$ & .00 & $.05 *$ & $4 \%$ \\
\hline & Spatial crowding & $.22 *$ & $-.17 *$ & $.05^{*}$ & $44 \%$ \\
\hline & Perceived control & $.62 *$ & - & $.62 *$ & - \\
\hline \multirow[t]{2}{*}{ Perceived control } & Human crowding & .00 & - & .00 & - \\
\hline & Spatial crowding & $-.28 *$ & - & $-.28 *$ & - \\
\hline
\end{tabular}

Notes. Alwin and Hauser (1975) suggest a formula to assess the relative importance of indirect effects: |indirect effect $\mid /($ indirect effect $|+|$ direct effect $\mid) . * \mathrm{p}<.05$-level. 
TABLE 5: RESULTS OF UNIVARIATE MODERATOR ANALYSIS

\begin{tabular}{|c|c|c|c|c|c|c|c|c|c|c|c|c|c|c|c|c|c|c|c|}
\hline \multirow{2}{*}{ Moderator } & \multirow[b]{2}{*}{ Level } & \multicolumn{6}{|c|}{ DV: Satisfaction } & \multicolumn{6}{|c|}{ DV: Behavioral intentions } & \multicolumn{6}{|c|}{ DV: Actual behavior } \\
\hline & & $\mathrm{rc}$ & $\mathrm{k}$ & $\mathrm{N}$ & $\mathrm{CI}_{\text {low }}$ & $\mathrm{CI}_{\text {high }}$ & Q & $\mathrm{rc}$ & $\mathrm{k}$ & $\mathrm{N}$ & $\mathrm{CI}_{\text {low }}$ & $\mathrm{CI}_{\text {high }}$ & Q & $\mathrm{rc}$ & $\mathrm{k}$ & $\mathrm{N}$ & $\mathrm{CI}_{\text {low }}$ & $\mathrm{CI}_{\text {high }}$ & Q \\
\hline \multicolumn{20}{|c|}{ IV: Human crowding } \\
\hline \multirow[t]{2}{*}{ Retail offering } & Hedonic & .03 & 9 & 1579 & -.15 & .21 & $89 *$ & $.11^{\mathrm{A}}$ & 12 & 2024 & -.07 & .28 & $158 *$ & $.23^{\mathrm{A}}$ & 6 & 671 & .09 & .38 & $17 *$ \\
\hline & Utilitarian & .07 & 16 & 4505 & -.05 & .18 & $189 *$ & $-.01^{\mathrm{A}}$ & 10 & 2188 & -.12 & .11 & $68^{*}$ & $.02^{\mathrm{A}}$ & 7 & 3148 & -.05 & .10 & $27 *$ \\
\hline \multirow[t]{2}{*}{ Retail type } & Single store & $.09^{\mathrm{A}}$ & 21 & 4673 & .00 & .20 & $224 *$ & $.03^{\mathrm{A}}$ & 19 & 3123 & -.10 & .16 & $231 *$ & $.13^{\mathrm{A}}$ & 11 & 2435 & .05 & .21 & $36^{*}$ \\
\hline & Agglomeration & $-.05^{\mathrm{A}}$ & 4 & 1411 & -.23 & .13 & $37 *$ & $.09^{\mathrm{A}}$ & 3 & 1089 & .02 & .17 & 4 & $-.07^{\mathrm{A}}$ & 2 & 1384 & -.09 & -.06 & 1 \\
\hline \multirow[t]{2}{*}{ Employee support } & High & $-.13^{\mathrm{A}}$ & 3 & 767 & -.37 & .11 & $26^{*}$ & .08 & 5 & 1167 & -.09 & .25 & $35^{*}$ & - & - & - & - & - & - \\
\hline & Low & $.08^{\mathrm{A}}$ & 22 & 5317 & .00 & .18 & $229 *$ & .03 & 17 & 3045 & -.10 & .17 & $201 *$ & .06 & 13 & 3819 & -.02 & .14 & $64 *$ \\
\hline \multirow[t]{2}{*}{ Customer type } & New & $-.04^{\mathrm{A}}$ & 7 & 2050 & -.17 & .08 & $43^{*}$ & $.08^{\mathrm{A}}$ & 11 & 1894 & -.12 & .27 & $164 *$ & $.17^{\mathrm{A}}$ & 1 & 247 & - & - & - \\
\hline & Existing & $.11^{\mathrm{A}}$ & 18 & 4034 & .00 & .23 & $211 *$ & $.02^{\mathrm{A}}$ & 11 & 2318 & -.09 & .14 & $71^{*}$ & $.05^{\mathrm{A}}$ & 12 & 3572 & -.03 & .13 & $61 *$ \\
\hline \multirow[t]{2}{*}{ Environment } & Cooperative & $.01^{\mathrm{A}}$ & 5 & 1395 & -.14 & .16 & $32 *$ & $.09^{\mathrm{A}}$ & 7 & 2073 & -.02 & .19 & $35^{*}$ & - & - & - & - & - & - \\
\hline & Competitive & $.07^{\mathrm{A}}$ & 20 & 4689 & -.04 & .18 & $244 *$ & $.01^{\mathrm{A}}$ & 15 & 2139 & -.16 & .18 & $197 *$ & .06 & 13 & 3819 & -.02 & .14 & $64 *$ \\
\hline Year & - & .18 & 25 & 6084 & .15 & .20 & - & .13 & 22 & 4209 & .10 & .16 & - & .24 & 13 & 3819 & .21 & .27 & - \\
\hline \multirow[t]{2}{*}{ Research design } & Experiment & $.02^{\mathrm{A}}$ & 9 & 2713 & -.13 & .16 & $109 *$ & .05 & 12 & 2526 & -.12 & .22 & $190 *$ & .06 & 2 & 847 & -.02 & .14 & 3 \\
\hline & Survey & $.09^{\mathrm{A}}$ & 16 & 3371 & -.03 & .22 & $162 *$ & .04 & 10 & 1686 & -.07 & .16 & $48^{*}$ & .06 & 11 & 2972 & -.04 & .15 & $61 *$ \\
\hline \multirow[t]{2}{*}{ Sample } & Students & $-.01^{\mathrm{A}}$ & 11 & 3101 & -.14 & .12 & $120 *$ & .02 & 5 & 1349 & -.15 & .18 & $42 *$ & .03 & 1 & 600 & - & - & - \\
\hline & Non-students & $.14^{\mathrm{A}}$ & 14 & 2983 & .01 & .27 & $131 *$ & .06 & 17 & 2863 & -.08 & .20 & $193 *$ & .07 & 12 & 3219 & -.03 & .16 & $63^{*}$ \\
\hline \multicolumn{20}{|c|}{ IV: Spatial crowding } \\
\hline \multirow[t]{2}{*}{ Retail offering } & Hedonic & -.27 & 4 & 267 & -.43 & -.12 & 5 & $-.21^{\mathrm{A}}$ & 9 & 1286 & -.39 & -.03 & $78 *$ & -.14 & 3 & 164 & -.23 & -.05 & 1 \\
\hline & Utilitarian & -.22 & 13 & 3545 & -.42 & -.02 & $369 *$ & $.16^{\mathrm{A}}$ & 5 & 1204 & .05 & .28 & $19 *$ & -.05 & 7 & 3148 & -.11 & .02 & $19 *$ \\
\hline \multirow{2}{*}{ Retail type } & Single store & $-.17^{\mathrm{A}}$ & 15 & 2937 & -.37 & .02 & $344 *$ & $-.10^{\mathrm{A}}$ & 12 & 1930 & -.25 & .06 & $125^{*}$ & - & - & - & - & - & - \\
\hline & Agglomeration & $-.42^{\mathrm{A}}$ & 2 & 875 & -.46 & -.38 & 1 & $.24^{\mathrm{A}}$ & 2 & 560 & .11 & .37 & $4^{*}$ & -.05 & 10 & 3312 & -.11 & -.00 & $21 *$ \\
\hline \multirow[t]{2}{*}{ Employee support } & High & $-.43^{\mathrm{A}}$ & 5 & 777 & -.57 & -.28 & $16^{*}$ & $-.11^{\mathrm{A}}$ & 5 & 1224 & -.39 & .17 & $96 *$ & - & - & - & - & - & - \\
\hline & Low & $-.17^{\mathrm{A}}$ & 12 & 3035 & -.39 & .04 & $328 *$ & $.05^{\mathrm{A}}$ & 9 & 1266 & -.10 & .20 & $61 *$ & -.05 & 10 & 3312 & -.11 & -.00 & $21 *$ \\
\hline \multirow[t]{2}{*}{ Customer type } & New & $-.46^{\mathrm{A}}$ & 2 & 334 & -.76 & -.16 & $12 *$ & $-.06^{\mathrm{A}}$ & 8 & 1648 & -.28 & .15 & $128 *$ & - & - & - & - & - & - \\
\hline & Existing & $-.20^{\mathrm{A}}$ & 15 & 3478 & -.39 & -.02 & $347^{*}$ & $.04^{\mathrm{A}}$ & 6 & 842 & -.14 & .22 & $39^{*}$ & -.05 & 10 & 3312 & -.11 & -.00 & $21 *$ \\
\hline \multirow[t]{2}{*}{ Environment } & Cooperative & -.14 & 1 & 103 & - & - & - & -.03 & 5 & 1311 & -.31 & .25 & $108 *$ & - & - & - & - & - & - \\
\hline & Competitive & -.23 & 16 & 3709 & -.41 & -.05 & $373 *$ & -.01 & 9 & 1179 & -.17 & .15 & $63^{*}$ & -.05 & 10 & 3312 & -.11 & -.00 & $21 *$ \\
\hline Year & - & -.39 & 17 & 3812 & -.42 & -.37 & - & -.45 & 14 & 2490 & -.49 & -.42 & - & -.42 & 10 & 3312 & -.45 & -.39 & - \\
\hline \multirow[t]{2}{*}{ Research design } & Experiment & $.04^{\mathrm{A}}$ & 5 & 1237 & -.36 & .45 & $234 *$ & $.01^{\mathrm{A}}$ & 9 & 2248 & -.17 & .19 & $148 *$ & $.08^{\mathrm{A}}$ & 1 & 600 & - & - & - \\
\hline & Survey & $-.39^{\mathrm{A}}$ & 12 & 2575 & -.44 & -.34 & 12 & $-.34^{\mathrm{A}}$ & 5 & 242 & -.46 & -.22 & 3 & $-.09^{\mathrm{A}}$ & 9 & 2712 & -.13 & -.05 & 8 \\
\hline \multirow[t]{2}{*}{ Sample } & Students & $-.16^{\mathrm{A}}$ & 9 & 2381 & -.43 & .12 & $333 *$ & $.19^{\mathrm{A}}$ & 3 & 1126 & .09 & .28 & $7 *$ & $.08^{\mathrm{A}}$ & 1 & 600 & - & - & - \\
\hline & Non-students & $-.36^{\mathrm{A}}$ & 8 & 1431 & -.44 & -.28 & $14 *$ & $-.22^{\mathrm{A}}$ & 11 & 1364 & -.37 & -.06 & $79 *$ & $-.09^{\mathrm{A}}$ & 9 & 2712 & -.13 & -.05 & 8 \\
\hline
\end{tabular}

$\mathrm{rc}=$ sample-weighted reliability adjusted average correlation; $\mathrm{k}=$ number of effect sizes; $\mathrm{N}=$ cumulative sample size; $\mathrm{CI}=95 \%$-confidence interval; $\mathrm{Q}=\mathrm{Q}$ statistic. The superscript (A) indicates a significant difference between moderator levels $(\mathrm{p}<.05)$. 
TABLE 6: SUMMARY OF HYPOTHESES TESTING

\section{Effect \\ MAIN EFFECTS ${ }^{a}$}

Outcomes

$\mathrm{HC} \rightarrow$ Actual behavior

$\mathrm{HC} \rightarrow$ Behavioral intentions

$\mathrm{HC} \rightarrow$ Satisfaction

$\mathrm{SC} \rightarrow$ Actual behavior

$\mathrm{SC} \rightarrow$ Behavioral intentions

$\mathrm{SC} \rightarrow$ Satisfaction

Mediators

$\mathrm{HC} \rightarrow$ Perceived control

$\mathrm{SC} \rightarrow$ Perceived control

$\mathrm{HC} \rightarrow$ Negative emotions

$\mathrm{HC} \rightarrow$ Positive emotions

$\mathrm{SC} \rightarrow$ Negative emotions

$\mathrm{SC} \rightarrow$ Positive emotions

$\mathrm{HC} \rightarrow$ Store evaluation

$\mathrm{SC} \rightarrow$ Store evaluation

MODERATION EFFECTS

Hedonic/utilitarian context

HC: Hedonic contex

SC: Hedonic context

Single store/agglomeration

HC: Single store

SC: Single store

Employee support

HC: Employee support

SC: Employee support

New/existing customer

HC: New customers

SC: New customer

Cooperative/competitive

HC: Cooperative

Prior studies

Prediction

Either positive or negative impact

Either positive or negative impact

Either positive or negative impact

Negative impact

Negative impact

Negative impact

Negative impact

Negative impact

Either positive or negative impact

Either positive or negative impact

Positive impact

Negative impact

Either positive or negative impact

Either positive or negative impact

Tests effect discussed in literature Not tested in prior literature

No effect proposed for HC

Proposes only an effect for SC

Tests effect discussed in literature Tests hypothesis for the first time

$\begin{array}{ccl}-\mathrm{ve} /+\mathrm{ve} & +(\mathrm{ns}) & \text { HC has a positive effect on actual behavior } \\ -/+ & +(\mathrm{ns}) & \text { HC has a positive effect on behavioral intentions } \\ -/+ & + \text { (ns) } & \text { HC has a positive effect on satisfaction } \\ - & - & \text { SC has a negative effect on actual behavior } \\ - & - \text { (ns) } & \text { SC has a negative effect on intentions } \\ - & - & \text { SC has a negative effect on satisfaction } \\ & & \\ - & - \text { (ns) } & \text { HC has a negative effect on control perceptions } \\ - & - & \text { SC has a negative effect on control perceptions } \\ +/- & + & \text { HC has a positive effect on negative emotions } \\ +/- & +(\mathrm{ns}) & \text { HC has a positive effect on positive emotions } \\ + & + & \text { SC has a positive effect on negative emotions } \\ - & + \text { (ns) } & \text { SC has a positive effect on positive emotions } \\ +/- & + & \text { HC has a positive effect on store evaluation } \\ +/- & -(n s) & \text { SC has a negative effect on store evaluation }\end{array}$

$\uparrow(\mathrm{H} 1 \mathrm{a})$

$\downarrow$ (H1b)

none

$\downarrow$ (H2)

$\uparrow(\mathrm{H} 3 \mathrm{a})$

$\downarrow$ (H3b)

Proposes only an effect for HC

$\downarrow$ (H4)

Not tested in prior literature

none

Proposes only an effect for HC

$\uparrow(\mathrm{H} 5)$

none

Not tested in prior literature

SC: Cooperative behavioral intentions turns positive for existing customers

are based on the descriptive statistics. +

$\uparrow \quad \mathrm{HC}$ has a stronger positive effect on intentions and behavior in hedonic than utilitarian contexts mixed SC has a negative effect on intentions in hedonic contexts and a positive in utilitarian

mixed $\mathrm{HC}$ has a stronger positive effect on intentions for agglomerations than single stores; however, the effects on satisfaction and behavior turn negative for agglomerations

mixed SC has a weaker negative effect on satisfaction for single stores than agglomerations; however, the effect on behavioral intentions turns positive for agglomerations

mixed $\mathrm{HC}$ has a negative effect on satisfaction for support and a positive without support

mixed SC has a stronger negative effect on satisfaction for employee support than without support; however, the effect on intentions is positive in contexts without support

mixed HC has a negative effect on satisfaction for new customers and a positive for existing; however, stronger positive effects on intentions and behavior were found for new customer

mixed SC has a stronger negative effect for new than existing customers; however, the effect on

mixed $\mathrm{HC}$ has a stronger positive effect on behavioral intentions for cooperative than competitive contexts; however, the opposite effect was found for satisfaction

ns No significant difference for cooperative versus competitive contexts

$+=$ positive effect; $-=$ negative effect; $\uparrow=$ stronger effect; $\downarrow=$ weaker effect 
TABLE 7: RESEARCH AGENDA ON CROWDING

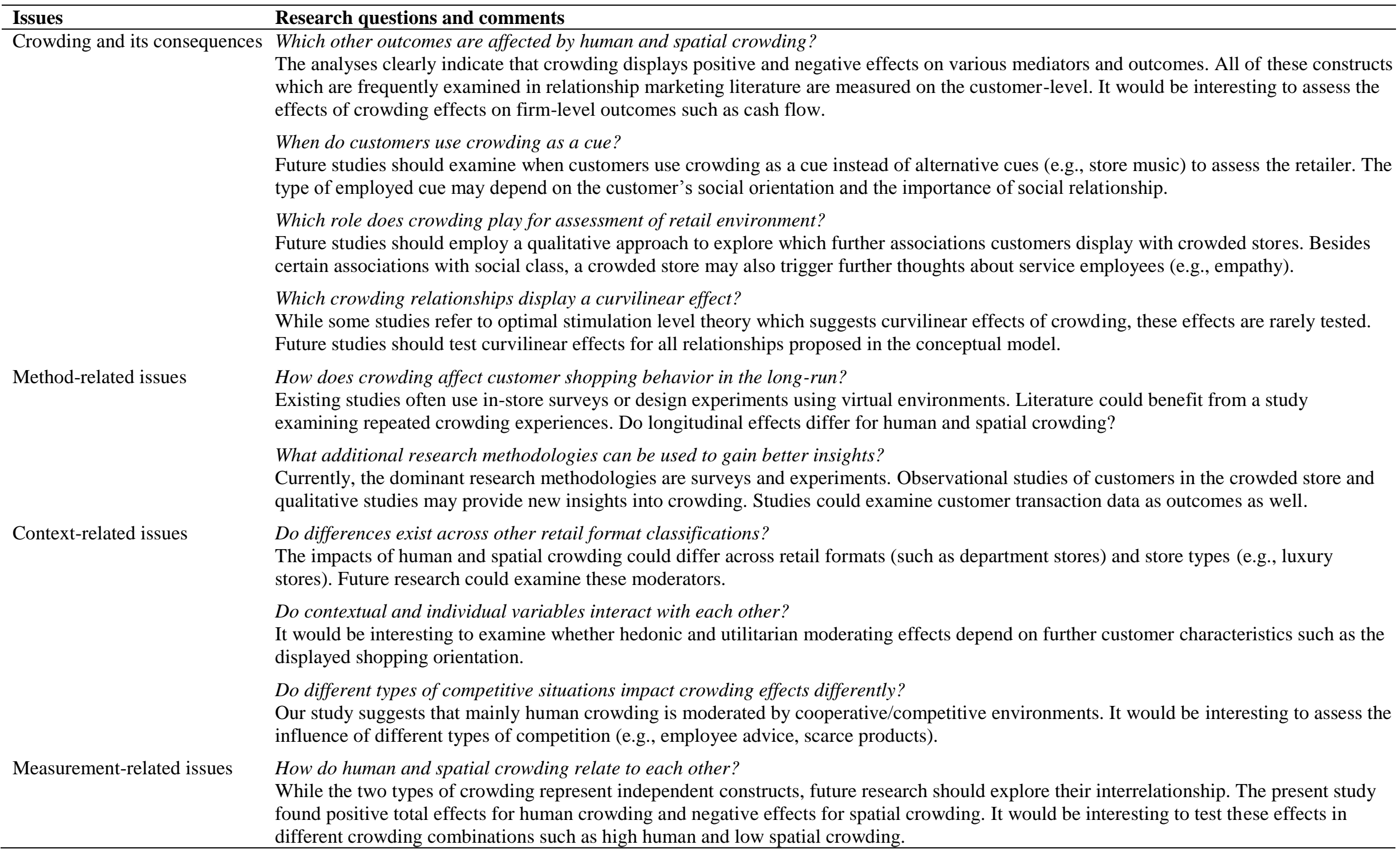


FIGURE 1

OVERVIEW OF DIFFERENT CROWDING THEORIES

Model 1

Coping Theory /

Optimal Social

Contact Model

Model 2

Perceived

Control Model

Emotional

Response Model

Model 4

Inference Theory
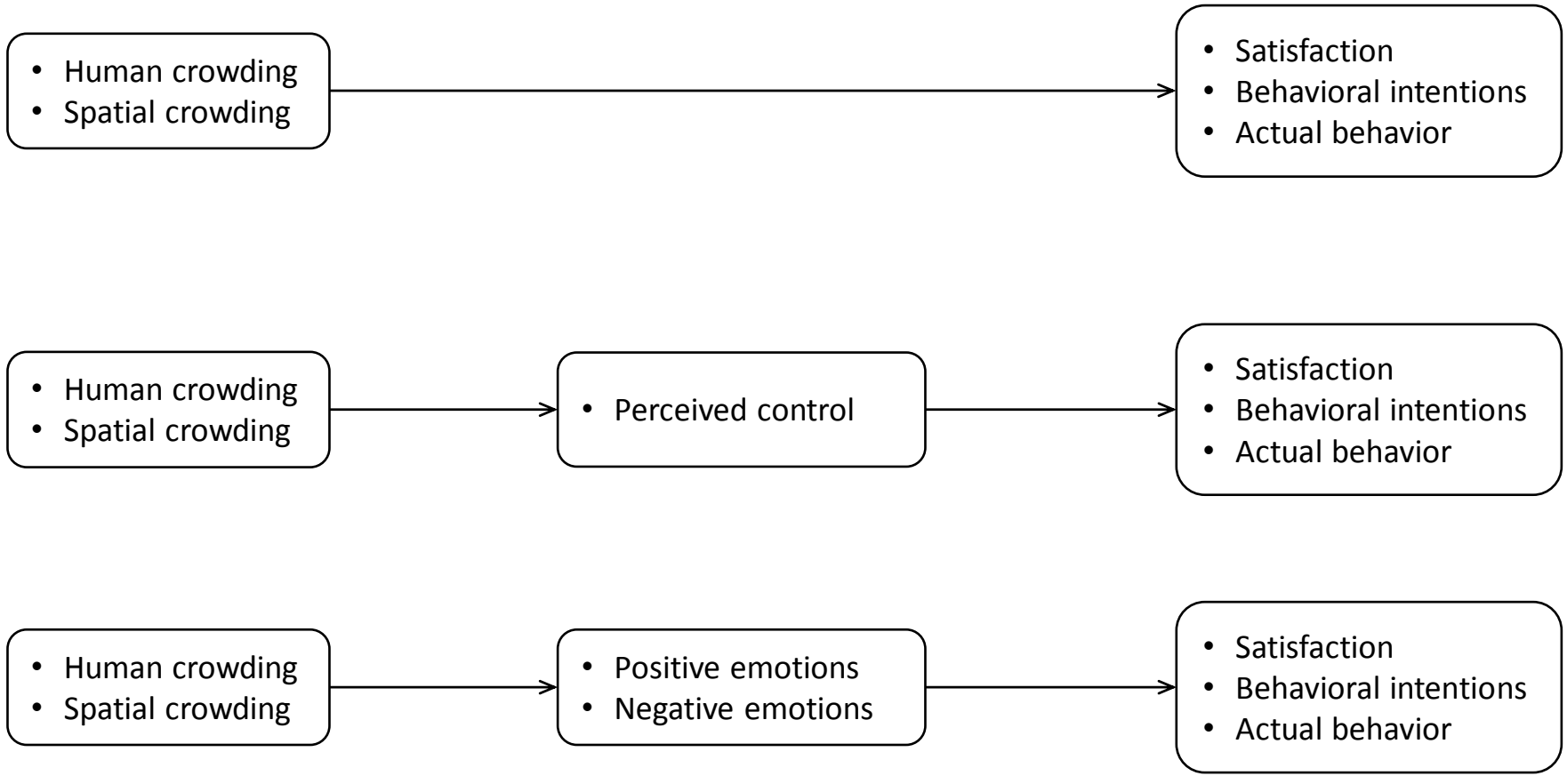

\begin{tabular}{|c|c|c|}
\hline - Human crowding & & Satisfaction \\
\hline - Spatial crowding & store evaluadion & - Actual behavior \\
\hline
\end{tabular}


FIGURE 2

INTEGRATED CONCEPTUAL MODEL

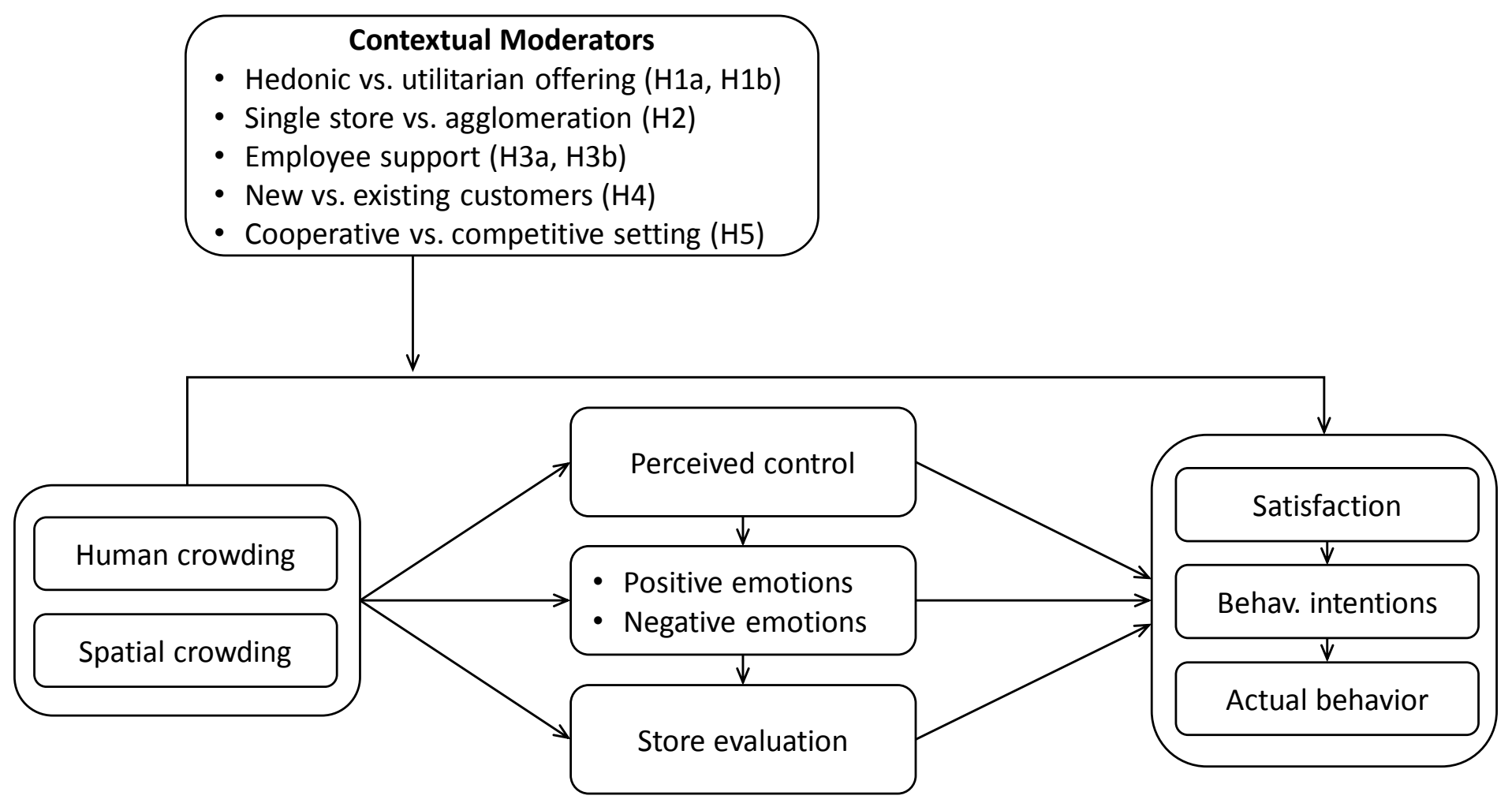

Notes: All constructs of the conceptual model were assessed in all analyses (e.g., descriptive statistics), except satisfaction which was not considered in the SEM. 